\title{
31 May 2013 El Reno Tornadoes: Advantages of Rapid-Scan Phased-Array Radar Data from a Warning Forecaster's Perspective*
}

\author{
CHARLES M. KUSTER \\ Cooperative Institute for Mesoscale Meteorological Studies, and NOAA/National Severe Storms Laboratory, \\ and University of Oklahoma, Norman, Oklahoma \\ PAMELA L. HEINSELMAN \\ NOAA/National Severe Storms Laboratory, and University of Oklahoma, Norman, Oklahoma \\ MARCUS AUSTIN \\ NOAA/National Weather Service, Norman, Oklahoma
}

(Manuscript received 24 October 2014, in final form 19 May 2015)

\begin{abstract}
On 31 May 2013, a supercell produced a tornado rated as 3 on the enhanced Fujita scale (EF3) near El Reno, Oklahoma, which was sampled by the S-band phased-array radar (PAR) at the National Weather Radar Testbed in Norman, Oklahoma. Collaboration with the forecaster who issued tornado warnings for the El Reno supercell during real-time operations focused the analysis on critical radar signatures frequently assessed during warning operations. The wealth of real-world experience provided by the forecaster, along with the quantitative analysis, highlighted differences between rapid-scan PAR data and the Weather Surveillance Radar-1988 Doppler located near Oklahoma City, Oklahoma (KTLX), within the context of forecast challenges faced on 31 May 2013. The comparison revealed that the 70-s PAR data proved most advantageous to the forecaster's situational awareness in instances of rapid storm organization, sudden mesocyclone intensification, and abrupt, short-term changes in tornado motion. Situations where PAR data were most advantageous in the depiction of storm-scale processes included 1) rapid variations in mesocyclone intensity and associated changes in inflow magnitude; 2) imminent radar-indicated development of the shortlived (EF0) Calumet, Oklahoma, and long-lived (EF3) El Reno tornadoes; and 3) precise location and motion of the tornado circulation. As a result, it is surmised that rapid-scan volumetric radar data in cases like this would augment a forecaster's ability to observe rapidly evolving storm features and deliver timely, life-saving information to the general public.
\end{abstract}

\section{Introduction}

To better understand an unpredictable atmosphere, meteorologists have created scientific conceptual models that aid in identifying favorable severe-weather environments and assist in overall threat recognition, including the potential for supercells and tornadogenesis

\footnotetext{
* Supplemental information related to this paper is available at the Journals Online website: http://dx.doi.org/10.1175/WAF-D-14-00142.s1.

Corresponding author address: Charles M. Kuster, National Weather Center, 120 David L. Boren Blvd., Norman, OK 73072. E-mail: charles.kuster@noaa.gov
}

(e.g., Johns and Doswell 1992; Doswell and Burgess 1993; Rasmussen 2003; Boustead et al. 2013). Such scientifically based conceptual models help forecasters anticipate future storm characteristics and develop predictions for potential hazards posed by storms (Andra et al. 2002), and act as building blocks for warning decisions, including warning type, location, and timing (Hahn et al. 2003). In National Weather Service (NWS) operations, progressively relating radar-based storm attributes and the near-storm environment to conceptual models is essential to successfully anticipating hazardous events and by extension accurate warnings (e.g., Andra et al. 2002; Lindley and Morgan 2004).

Advancements in radar technology have contributed to the development of tornadic supercell conceptual 
models and their operational applications (e.g., Wilson et al. 1980; Crum and Alberty 1993; Vasiloff 2001; Scharfenberg et al. 2005). Early research with Doppler radars showed that mesocyclone intensification was associated with the presence of strong low-level inflow and that the development of the rear-flank downdraft (RFD) may signal an increase in tornado potential (Brandes 1978, 1984). The tornadic vortex signature (TVS) served as another indication of a storm's increased tornado potential (Brown et al. 1978). While the detection of a TVS or its descent (e.g., Lemon et al. 1978) does not guarantee surface tornadogenesis, its existence can increase confidence in the warning process, especially when the storm is closer to the radar where sampling is better able to depict a TVS. During the late 1970s, the Joint Doppler Operational Project (e.g., Burgess et al. 1979) examined the operational benefits of Doppler radar and found that tornado warnings issued using this technology had longer lead times and lower false alarm rates than those issued using only the Weather Surveillance Radar-1957 network. The analysis of two operational tornadic cases by Dunn (1990) found that the Doppler velocity field revealed clear circulations located in an echo-free region beneath a high-reflectivity overhang, confirming the existence of the rotating updraft depicted in supercell conceptual models. Forecasters successfully issued several tornado warnings prior to tornado development when able to observe these key elements (Dunn 1990).

Numerical simulation studies (e.g., Klemp and Rotunno 1983; Wicker and Wilhelmson 1995; Trapp and DaviesJones 1997; Adlerman et al. 1999; Trapp 2000; DaviesJones 2008; Naylor and Gilmore 2014) have further advanced these early radar-based conceptual models by providing insight into the evolution of three-dimensional airflow within supercells prior to and during tornadogenesis. One example is the analysis of the interconnections between rotation intensity, updraft strength, and low-level convergence by Wicker and Wilhelmson (1995). Owing to these interconnections in the conceptual model, a forecaster who observes increasing mesocyclone rotation, indications of strong updraft pulses, and increasing low-level convergence along the leading edge of the RFD may have higher confidence in tornado-warning issuance (e.g., Heinselman et al. 2015).

More recently, high-resolution (spatial and temporal) radar data collected by mobile radars have provided additional storm-scale information that can be used to refine existing conceptual models. For example, analyses of mobile radar datasets of tornadogenesis show the TVS building upward or intensifying at multiple heights simultaneously (e.g., French et al. 2013, 2014), suggesting that the conceptual model of TVS descent (e.g., Lemon et al. 1978) may be a result of temporal limitations of the
Weather Surveillance Radar-1988 Doppler (WSR-88D) network (French et al. 2013). Analyses of mobile radar data have further emphasized the importance of RFDs to tornadogenesis, such as low-level convergence along the secondary rear-flank gust front (e.g., Wurman et al. 2007a; Kosiba et al. 2013) and during cyclic mesocyclogenesis (Dowell and Bluestein 2002). In NWS operations, the availability of C-band Terminal Doppler Weather Radar data at some offices (e.g., Vasiloff 2001), and more frequent, superresolution sampling by the WSR-88D at lowelevation angles via new volume scanning strategies, such as Automated Volume Scan Evaluation and Termination (AVSET) and Supplemental Adaptive Intravolume LowLevel Scans (SAILS), can help to better resolve such features (Brown et al. 2005a; Wood et al. 2009; Chrisman 2009; Crum et al. 2013).

The research S-band phased-array radar (PAR) at the National Weather Radar Testbed (Zrnić et al. 2007) has collected high temporal-resolution data that aids in our understanding of rapidly evolving features of examined severe storms (Heinselman et al. 2008; Emersic et al. 2011; Newman and Heinselman 2012; Tanamachi et al. 2015). LaDue et al. (2010) noted the relevance of temporal sampling to forecasters' ability to apply conceptual models during operations, based on interviews conducted with NWS forecasters in the southern plains region. In some instances, the forecasters knew how a storm was likely evolving by applying conceptual models, but the WSR88D network could not always capture storm trends at the required time scales. Heinselman et al. $(2012,2015)$ and Bowden et al. (2015) further confirmed this challenge during the 2010, 2012, and 2013 Phased-Array Radar Innovative Sensing Experiments (PARISE). Using simulated real-time cases, forecasters participating in PARISE reported that rapid (e.g., $1 \mathrm{~min}$ ) volumetric update times depicted more fluidlike storm evolutions that more closely matched their conceptual models compared to 4-5-min volumetric updates provided by the WSR-88D. The rapid scanning ability of PAR allowed the forecaster to more effectively apply conceptual models, resulting in superior warning decision lead times for low-end tornado (Heinselman et al. 2012, 2015) and severe hail and wind cases (Bowden et al. 2015) compared to WSR-88D-like sampled events.

Given the focus of previous tornado-related PAR studies on marginal tornadic events (e.g., Heinselman et al. 2012, 2015), how such rapid-update radar data may be beneficial to a forecaster during a higher-end tornado event has not been addressed. In some cases, environmental conditions suggest enhanced tornado potential, which can increase confidence in issuing tornado warnings earlier in a storm's life cycle, potentially decreasing the impact of rapid-update radar data on tornado-warning 
TABLE 1. Basic characteristics of the PAR and WSR-88D on 31 May 2013.

\begin{tabular}{lll}
\hline \multicolumn{1}{c}{ Characteristics } & \multicolumn{1}{c}{ PAR } & \multicolumn{1}{c}{ WSR-88D (KTLX) } \\
\hline Antenna & Planar (electronically scanned) & Parabolic (mechanically scanned) \\
Wavelength $(\mathrm{cm})$ & 9.38 & 10 \\
Polarization & Vertical & Dual \\
Transmitting beamwidth $\left(^{\circ}\right)$ & 1.5 at bore site and 2.1 at \pm 45 & 1.0 \\
Range sampling $(\mathrm{m})$ & 240 & 250 \\
Elev angles $\left({ }^{\circ}\right)$ & $0.5,0.9,1.3,1.8,2.4,3.1,4.0,5.1,6.4,8.0$, & $0.5,0.9,1.3,1.8,2.4,3.1,4.0,5.1,6.4,8.0$, \\
& $10.0,12.5,15.6,19.5,23.4,28.2,34.2$, & $10.0,12.5,15.6$, and 19.5 \\
& 42.8, and 52.9 & 4.16 (for $360^{\circ}$ sector) \\
\hline
\end{tabular}

lead time (e.g., Moller et al. 1994; Andra et al. 2002). While rapid-update radar data may not significantly impact when a forecaster ultimately warns during highend tornado events, it could impact how a forecaster understands storm evolution within the context of his or her conceptual model. Better sampling of crucial conceptual model components may allow forecasters to more readily recognize potential threats and intelligently anticipate storm evolution (Andra et al. 2002), enabling them to more effectively communicate warning information to the general public. Such information includes the temporal and spatial extent of a tornado warning; updates regarding tornado occurrence, location, and motion (severe-weather statements); and the issuance and cancellation of tornado emergencies (OFCM 2010; NOAA 2012).

On 31 May 2013, the development of a supercell that produced a 16.2-mi-long and 2.6-mi-wide tornado with maximum damage rated as 3 on the enhanced Fujita scale (EF3) near El Reno, Oklahoma (NCDC 2013; Marshall et al. 2014; Wurman et al. 2014), was sampled every $70 \mathrm{~s}$ by PAR. The tornado resulted in the deaths of eight motorists and produced extensive crop and property damage (NCDC 2013). The purpose of this study is to compare the storm evolution depicted by rapid-scan PAR data and data collected by the WSR-88D near Oklahoma City, Oklahoma (KTLX), to assess any differences and their relevance to warning operations during a significant tornado event. This goal was accomplished by collaborating with a forecaster who has intimate real-world experience of this event. The advantages and limitations of this approach are discussed in section $2 \mathrm{~b}$. The forecaster compared the evolution of radar signatures depicted by PAR and the WSR-88D used during operations (KTLX) for the period extending from about $40 \mathrm{~min}$ prior to tornadogenesis through the dissipation stage of the El Reno tornado (2221-2347 UTC 31 May 2013). This approach focused the study on critical storm features frequently assessed during warning operations (e.g., inflow magnitude and mesocyclone strength). The quantitative analysis objectively illustrates differences between PAR and KTLX's sampling of key storm features identified as significant by the forecaster. Therefore, this study benefits from a blending of operational and research expertise to illuminate any differences in the depiction of storm evolution sampled by PAR during this significant tornado event and their relevance and implications to operations.

\section{Data and methods}

\section{a. Radar data}

PAR is a research radar that operates using an electronically scanned U.S. Navy SPY-1A S-band planar antenna; it is located in Norman, Oklahoma, at the National Weather Radar Testbed (Table 1; Forsyth et al. 2005; Zrnić et al. 2007). The transmit beamwidth varies from $1.5^{\circ}$ at bore sight to $2.1^{\circ}$ at $\pm 45^{\circ}$ across a $90^{\circ}$-azimuthal sector. During this event, PAR used 19 elevation angles, which included those defined in volume coverage pattern (VCP) 12 (Brown et al. 2005b) plus 5 elevation angles above $19.5^{\circ}$ (Table 1). The volumetric update time of PAR was $1.16 \mathrm{~min}(70 \mathrm{~s})$. KTLX is a WSR-88D operated by the National Weather Service (Whiton et al. 1998). The radar uses a mechanically steered parabolic S-band antenna with dual polarization, and is located southeast of Oklahoma City, approximately $20 \mathrm{~km}$ northeast of PAR (Fig. 1). During this event, KTLX utilized VCP 212 (OFCM 2013), which provided a $360^{\circ}$ volumetric update time of about $4.58 \mathrm{~min}$.

\section{b. Methods}

Forecaster and research scientist knowledge of tornado outbreaks, especially one as well publicized as that on 31 May 2013, is very difficult to prevent. While one may argue that working with a severe-storms forecaster without the bias of a priori knowledge of this event would be ideal, doing so would be very challenging. Furthermore, there are numerous advantages to working with a forecaster with real-time experience.

In this case, having worked the event and issued the warnings on the El Reno storm, the forecaster was 


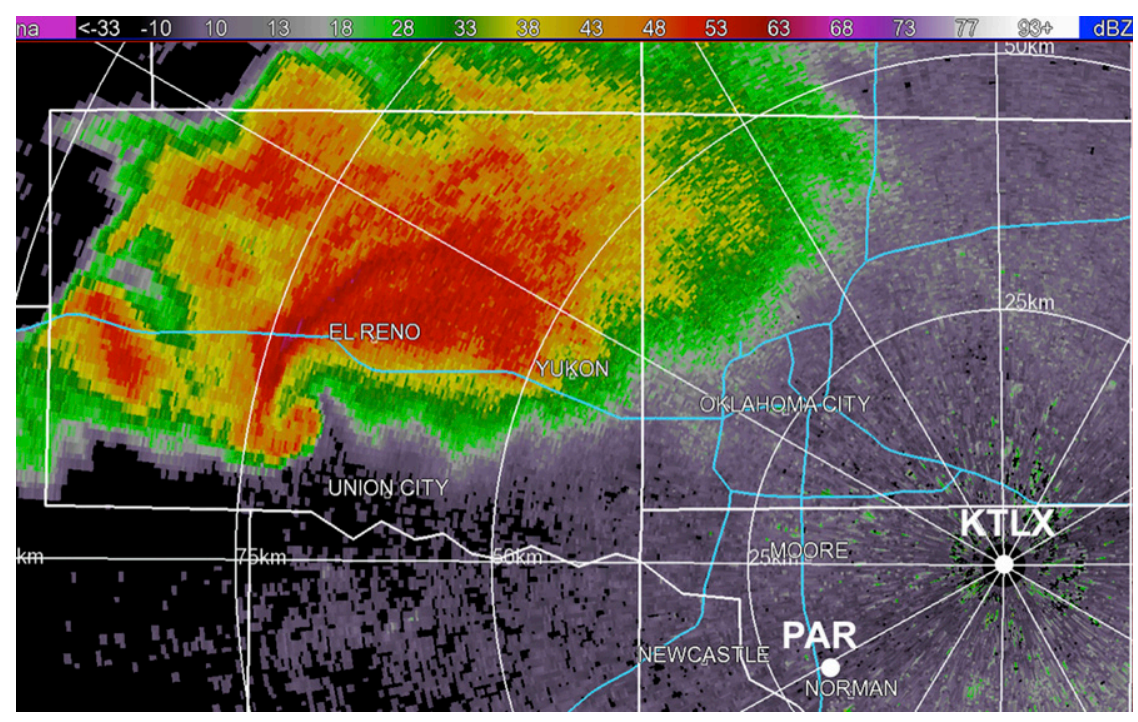

FIG. 1. Locations of PAR and KTLX (solid white circles) relative to the supercell of interest at 2309:57 UTC 31 May 2013. The white rings are displayed at 25-km increments.

familiar with the environmental conditions, aware of the forecast office's warning philosophy on 31 May 2013, and able to easily recount forecast challenges impactful to warning operations. This wealth of real-world experience allowed us to focus the radar data comparison on forecast challenges faced during operations and to assess any differences found within this context. Had the research focus been on forecaster performance or decision-making based on the use of PAR data, an approach similar to a previous PARISE (e.g., Heinselman et al. 2015; Bowden et al. 2015) would have been more appropriate.

Before the forecaster interacted with the radar data, the velocity field was manually dealiased (i.e., corrected for velocity folding to make mesocyclone signatures easier to interpret) using NCAR's SOLO software (Oye et al. 1995). During the interview process, special care was taken in keeping the data collection as objective as possible by asking open-ended questions. Questions and tasks were also ordered to minimize bias in the forecaster's responses. First, the forecaster was asked to recall the challenges he encountered during operations and to point out and describe key aspects of his tornadic supercell conceptual model seen in the KTLX data, which he viewed during this process to help jog his memory. Thereafter, the forecaster was provided with PAR data and asked to point out any differences in storm evolution compared to KTLX data, and whether or not he thought those differences were relevant to the challenges he faced during operations. Following the interview, differences evaluated as most significant by the forecaster became the focus of this study and our interactions with him became collaborative.
Of particular importance to the forecaster was the ability to observe key changes to velocity signatures significant to his tornadogenesis conceptual model (e.g., inflow magnitude, mesocyclone intensity, and rear-flank downdraft evolution). Many of these changes were seen earlier and sometimes only in PAR data, compared to KTLX data. Differences found were also examined by completing a quantitative analysis (i.e., time trends of inflow and mesocyclone magnitude). Although efforts were made to compute these time trends at similar heights, dissimilarities in radar location and sampling characteristics (Table 1, Fig. 1) negated exact matching of resolution volumes. Hence, the comparative analysis focused on differences in trends rather than on exact values.

\section{Environmental setting and expectations}

The 1800 UTC 31 May 2013 Norman sounding indicated the presence of a strongly unstable environment (Fig. 2a) with surface-based convective available potential energy exceeding $5000 \mathrm{~J} \mathrm{~kg}^{-1}$ and low- and midlevel lapse rates of approximately $7^{\circ}-8^{\circ} \mathrm{C} \mathrm{km}^{-1}$. Deep-layer $(0-6 \mathrm{~km})$ shear values of $20.6-25.7 \mathrm{~m} \mathrm{~s}^{-1}$ [40-50 knots $\left(\mathrm{kt}\right.$; where $\left.\left.1 \mathrm{kt}=0.51 \mathrm{~m} \mathrm{~s}^{-1}\right)\right]$ were conducive to rapid storm organization and supercell development. Although the environment was weakly capped with $74 \mathrm{~J} \mathrm{~kg}^{-1}$ of convective inhibition in the mixed layer, several hours passed before storms initiated around 2130 UTC. The one factor limiting the tornado threat was relatively weak low-level stormrelative helicity (e.g., Kerr and Darkow 1996) prior to storm initiation. 

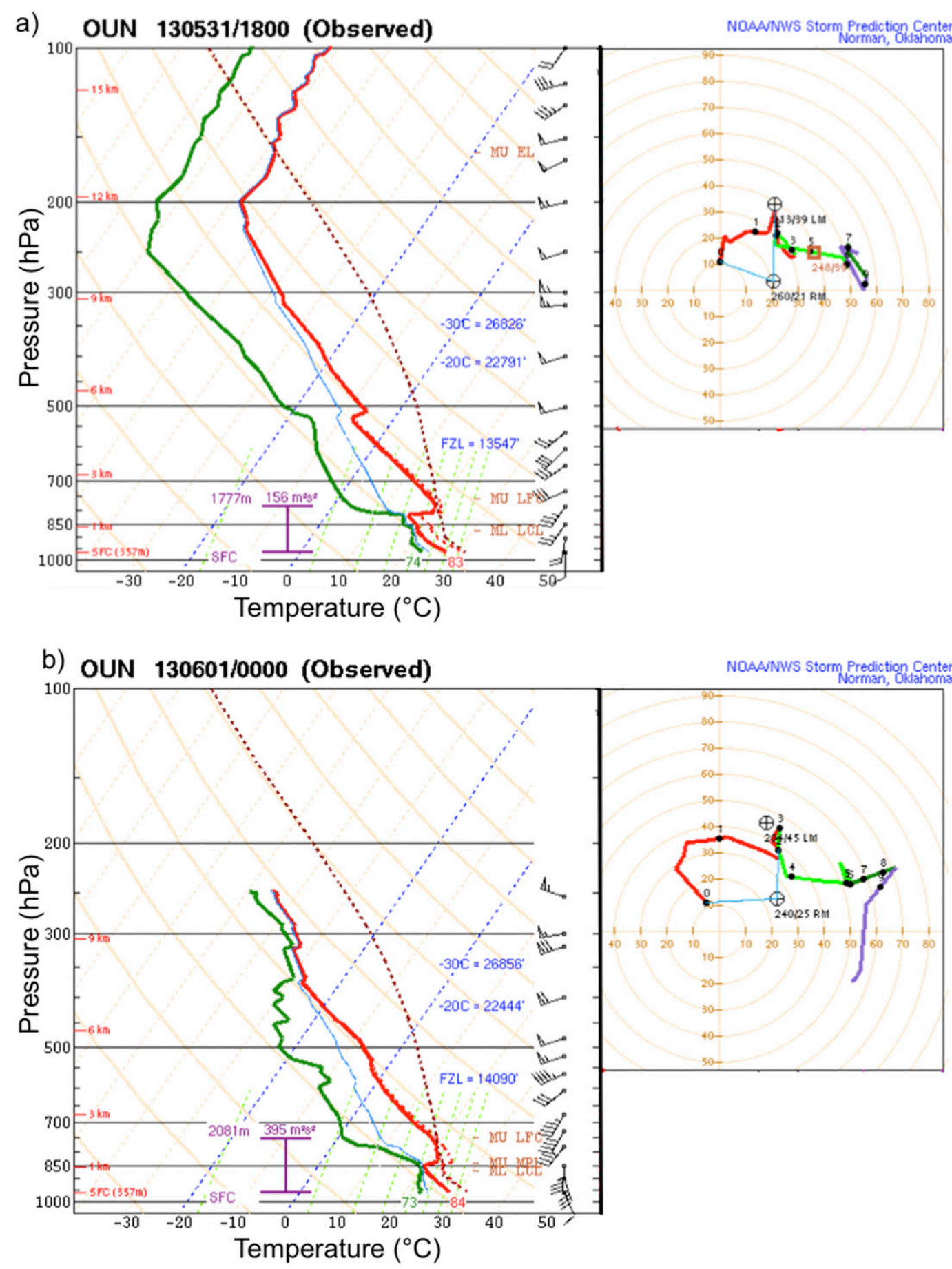

FIG. 2. Soundings and hodographs at (a) 1800 UTC 31 May and (b) 0000 UTC 1 Jun 2013 for Norman, obtained from the Storm Prediction Center. Red line is temperature and green line is dewpoint temperature. The vertical purple bar denotes the depth of the effective inflow layer, and the value above is the storm-relative helicity within that layer $\left(\mathrm{m}^{2} \mathrm{~s}^{-2}\right)$. More information on the content within these images is available online (http://www.spc.noaa.gov).

At the Norman Weather Forecast Office, forecasters monitored mesoscale conditions for indications of a more favorable tornado environment as the afternoon progressed. In particular, backing of surface winds and backing and/or increasing low-level wind fields would promote the higher low-level storm-relative helicity essential for the development of low-level mesocyclones and tornadoes (e.g., Brooks et al. 1993, 1994; Kerr and 


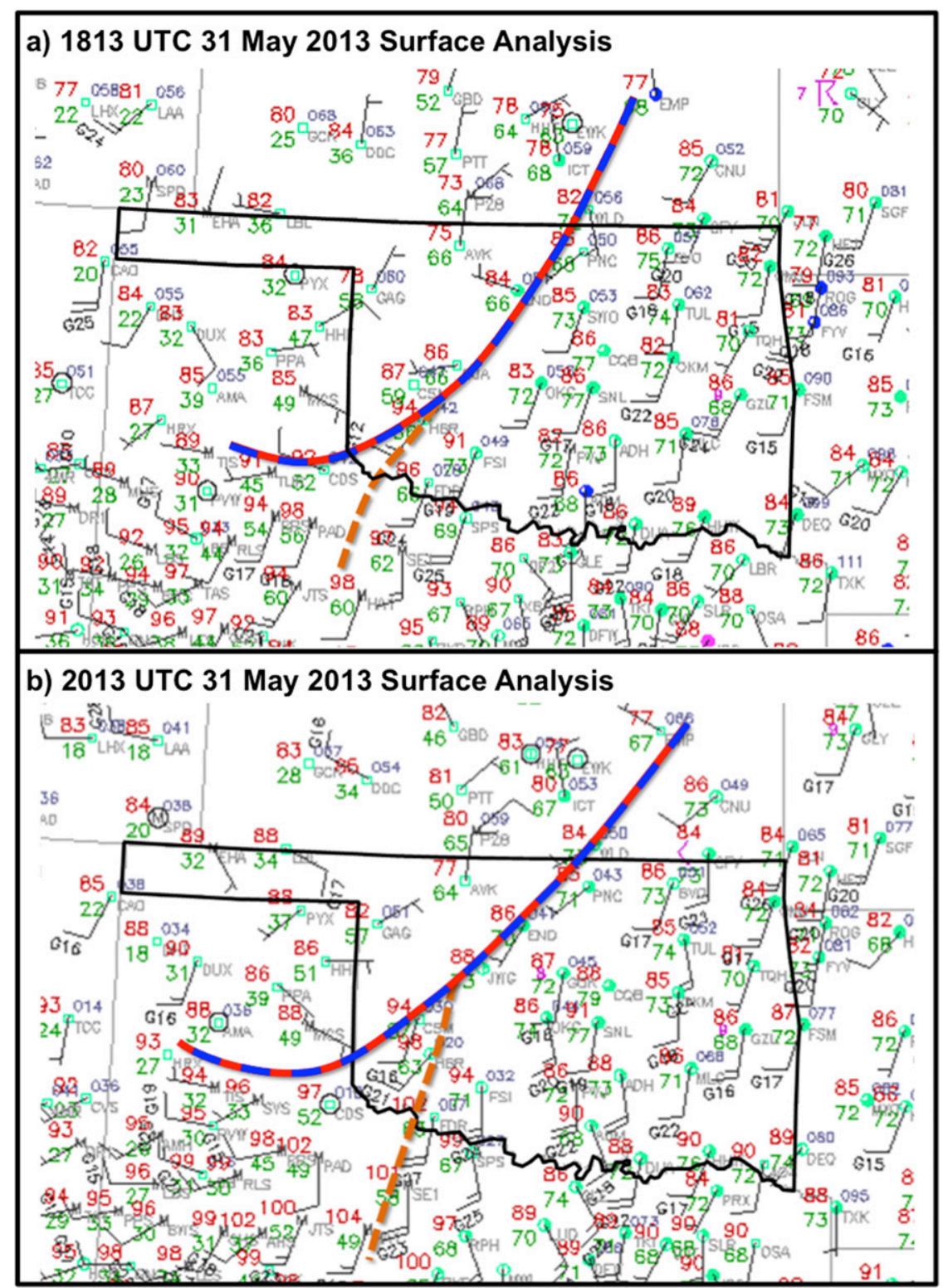

FIG. 3. Surface observations at (a) 1813 and (b) 2013 UTC 31 May 2013 annotated with the location of the stationary surface front (blue-red line) and dryline (dashed brown line). Station surface observations are temperature $\left({ }^{\circ} \mathrm{F} ; \mathrm{red}\right)$, dewpoint temperature $\left({ }^{\circ} \mathrm{F}\right.$; green $)$, pressure $(\mathrm{hPa}$; gray), wind speed and direction ( $\mathrm{kt}$; full barb $=10 \mathrm{kt}$ ), and gusts (gray letter "G"). Data are taken from the UCAR image archive available online (http://www.mmm.ucar.edu/imagearchive/).

Darkow 1996). Between 1813 and 2013 UTC, these conditions were realized (Fig. 3). Surface low pressure deepened at the intersection of a dryline and a stalled front over western Oklahoma, and surface winds gradually backed, with south-southwesterly winds becoming southeasterly by 2013 UTC (Fig. 3). In addition, the $850-\mathrm{hPa}$ winds shifted from west-southwest to southsouthwest (not shown). Forecasters recognized this backing of surface and low-level wind fields as an indication that the potential for strong to violent tornadoes had significantly increased prior to storm initiation. They determined with increasing confidence that it was not a matter of if a violent tornado would occur, but a matter of when and where it would form in Oklahoma, given the volatility of the environment.

As anticipated by forecasters, the 0000 UTC 1 June 2013 Norman sounding (Fig. 2b) depicted an environment even more conducive to tornadogenesis. Strong instability and deep-layer wind shear remained, and a comparison of the 1800 and 0000 UTC soundings 
revealed a substantial increase in the $0-1-$ and $0-3-\mathrm{km}$ stormrelative helicity (from 113 and $182 \mathrm{~m}^{2} \mathrm{~s}^{-2}$ at 1800 UTC 31 May to 294 and $403 \mathrm{~m}^{2} \mathrm{~s}^{-2}$ at 0000 UTC 1 June 2013, respectively). Furthermore, the hodograph indicated a favorable environment for strong to violent longtrack tornadoes (Fig. 2b; e.g., Kerr and Darkow 1996; Markowski et al. 2003; Esterheld and Guiliano 2008). The El Reno tornado had already occurred when the sounding observations were collected, and other tornadic supercells were ongoing over the Oklahoma City metropolitan area. During real-time operations, these shortterm changes in mesoscale weather features from 1800 to 0000 UTC resulted in dramatic differences in severeweather expectations, and were critical in forming assumptions that shaped the warning decision process.

\section{Forecaster's determination of operational benefits of rapid-scan PAR data}

\section{a. Differences in storm evolution relevant to forecast challenges}

An important consideration in the warning process is how quickly storms will organize and, if multiple storms are present, which of them are most likely to produce significant severe weather. These considerations are even more important in an environment strongly supportive of rapid storm organization and supercell development. On 31 May 2013, KTLX sampled a line of storms that began to form around 2130 UTC (Fig. 4a) along the stalled front positioned from southwest to northeast across central Oklahoma (Fig. 3). These storms quickly intensified, and the first severe thunderstorm warning was issued $15 \mathrm{~min}$ later, at 2146 UTC (Fig. 4b). By 2214 UTC, many of the storms had merged into disorganized storm clusters (Fig. 4c).

As the storms continued to mature, the next forecast challenge was to assess which storms would be most capable of producing tornadoes. The most obvious candidate for potential tornado formation was the "tail-end Charlie" storm to the west of Union City, Oklahoma, since it had unimpeded access to warm moist air residing south of the thunderstorm complex (Branick 1996). This storm later became the most significant storm of the day-the El Reno tornadic supercell.

The first tornado warning was issued at 2236 UTC with high confidence owing to the development of more pronounced rotation within the storm's cyclonically convergent velocity signature, in a near-storm environment highly supportive of rapid tornado development. The key evolution in the KTLX data that led to this trigger point was the transition of a contracting convergent velocity signature (2224:12 UTC; $\sim 1.3 \mathrm{~km}$ at $0.5^{\circ}$; see Fig. $\left.5 f\right)$ to a cyclonically convergent signature (2228:49 UTC; Fig. 5g), which then developed more pronounced rotation within that cyclonically convergent signature (2233:26 UTC; Fig. 6g). During this period, a comparison of the evolution seen in the KTLX and PAR data revealed that PAR depicted the process of these transitions (Figs. 5a-e and $6 a-e ;$ please see animations for these figures in the supplemental material), whereas the KTLX data depicted snapshots of the evolving velocity signatures (Figs. 5f-g and $6 \mathrm{f}-\mathrm{g}$ ). Since PAR data showed a more complete picture of the velocity signature's evolution, in a similar environment, the minute-by-minute observation of an organizing supercell could increase confidence in initial tornado-warning issuance.

\section{b. Mesocyclone cycles and tornado occurrence}

Once the tornado warning was issued, attention shifted to monitoring aspects of the storm conducive to tornado formation, such as the rotational magnitude of the low- and midlevel mesocyclones, the presence of a well-defined RFD, and the intensity of the updraft inferred from radar signatures [e.g., bounded weakecho region (BWER) and magnitude and extent of the storm's inflow]. In the comparative analysis, the PAR data were found to be important to understanding this evolution and the timing of tornado development. In particular, the 70-s updates better depicted the development, intensification, and dissipation of midlevel and low-level mesocyclones, tornadic vortex signatures, and variations in storm inflow. To more easily compare these differences in storm evolution, the rotational and inflow intensity (i.e., spatial extent and magnitude) were quantified and trends were examined. Mesocyclone rotational intensity was estimated by computing the gate-to-gate change in radial velocity (hereafter DeltaV), which is defined as the sum of the maximum in- and outbound velocities of adjacent range gates (Burgess et al. 1975). The spatial extent of the inflow region, at elevations $2.4^{\circ}$ and lower, was quantified by counting the number of range gates with radial velocities $20 \mathrm{~m} \mathrm{~s}^{-1}$ or higher within the supercell's inflow sector, while magnitude was quantified by calculating the mean value of these range gates.

During the early phases of supercell organization (2232-2241 UTC), both KTLX and PAR depicted the development and intensification of the first midlevel mesocyclone $[\sim 3 \mathrm{~km}$ above radar level (ARL)] prior to the nontornadic low-level mesocyclone at $0.5^{\circ}$ ( $\sim 1 \mathrm{~km}$ ARL; Fig. 7). Comparison of the first mesocyclones' DeltaV trends indicates KTLX sampled only one increase in low- and midlevel mesocyclone intensity, whereas PAR sampled two (Fig. 7). The initial increase in DeltaV at $0.5^{\circ}$ (2236-2241 UTC) 
KTLX

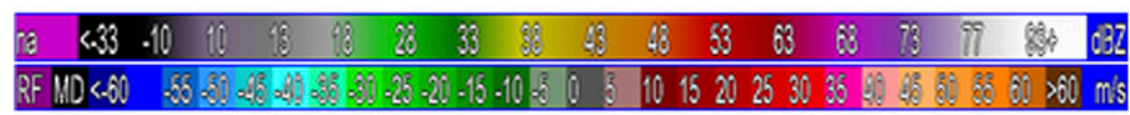
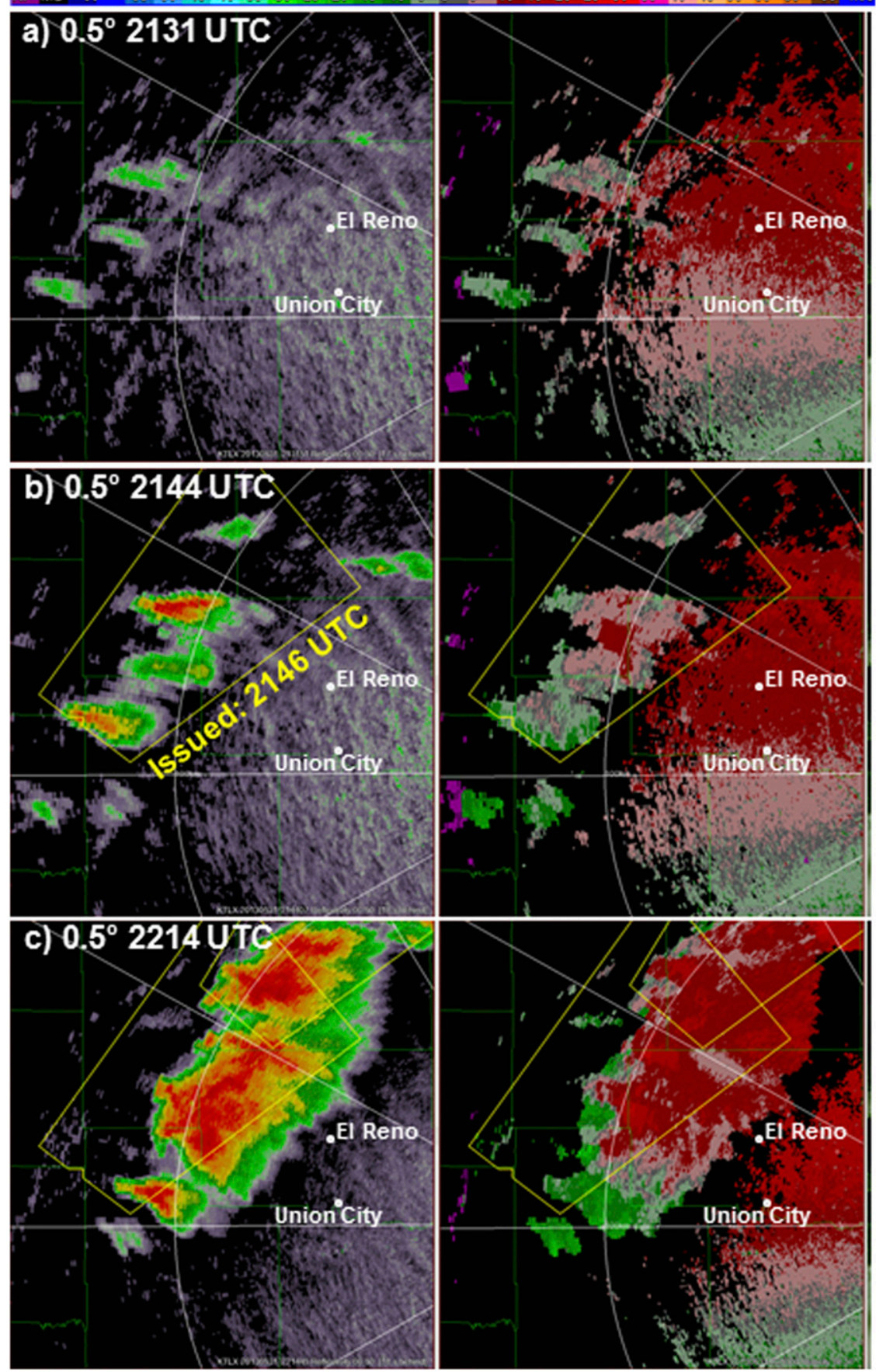

FIG. 4. KTLX $0.5^{\circ}$ (left) base reflectivity and (right) velocity at (a) 2131, (b) 2144, and (c) 2214 UTC 31 May 2013. Reflectivity (dBZ) and velocity $\left(\mathrm{m} \mathrm{s}^{-1}\right)$ color bars are provided. The white ring is $100 \mathrm{~km}$ in range from KTLX. Severe warnings are denoted by yellow polygons. The second severe warning in (c) was issued at 2214 UTC. 


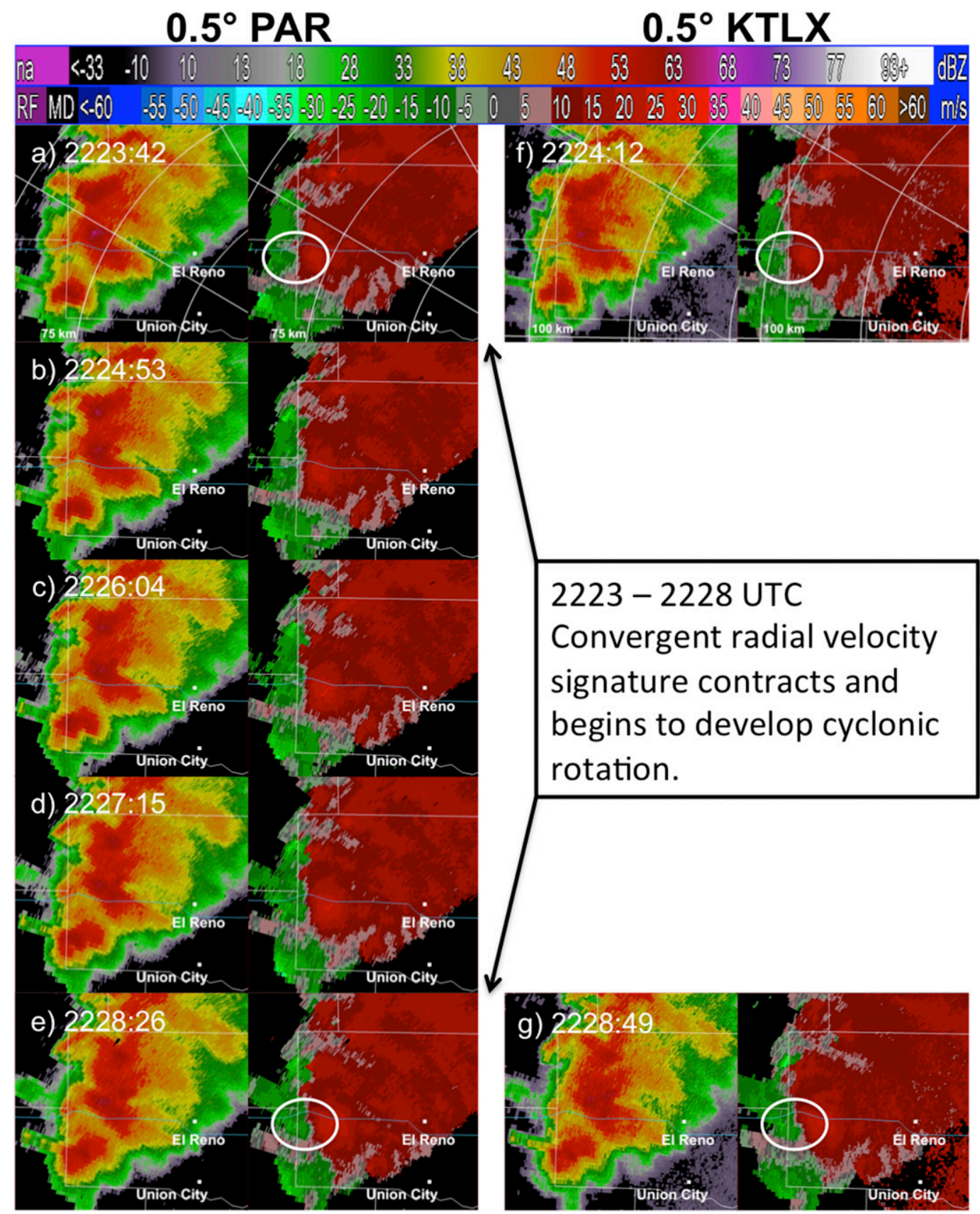

FIG. 5. (a)-(e) PAR and (f),(g) KTLX $0.5^{\circ}$ (left) base reflectivity and (right) velocity at (a) 2223:42, (b) 2224:53, (c) 2226:04, (d) 2227:15, (e) 2228:26, (f) 2224:12, and (g) 2228:49 UTC 31 May 2013. Reflectivity (dBZ) and velocity $\left(\mathrm{m} \mathrm{s}^{-1}\right)$ color bars are provided. Distance from PAR to convergent signature is $82 \mathrm{~km}$ and distance from KTLX to convergent signature is $95 \mathrm{~km}$. White rings [in (a) and (f)] show range from radar in $25-\mathrm{km}$ increments and white lines are azimuth angles from radar in $30^{\circ}$ increments. White circles indicate beginning and ending locations of the feature of interest.

corresponded well with an initial increase in the spatial extent and magnitude of the supercell's inflow region at $0.5^{\circ}$ and $0.9^{\circ}$ (Figs. 7-9), which indirectly indicated a rapidly strengthening updraft and potential of contracting and increasing low-level rotation.
During the next $10 \mathrm{~min}(2242-2252$ UTC), PAR's eight volume scans portrayed a storm merger occurring along the southern flank of the supercell (Fig. 10); this storm merger was more difficult to discern in the KTLX data (Fig. 10; please see animation for this figure in the 


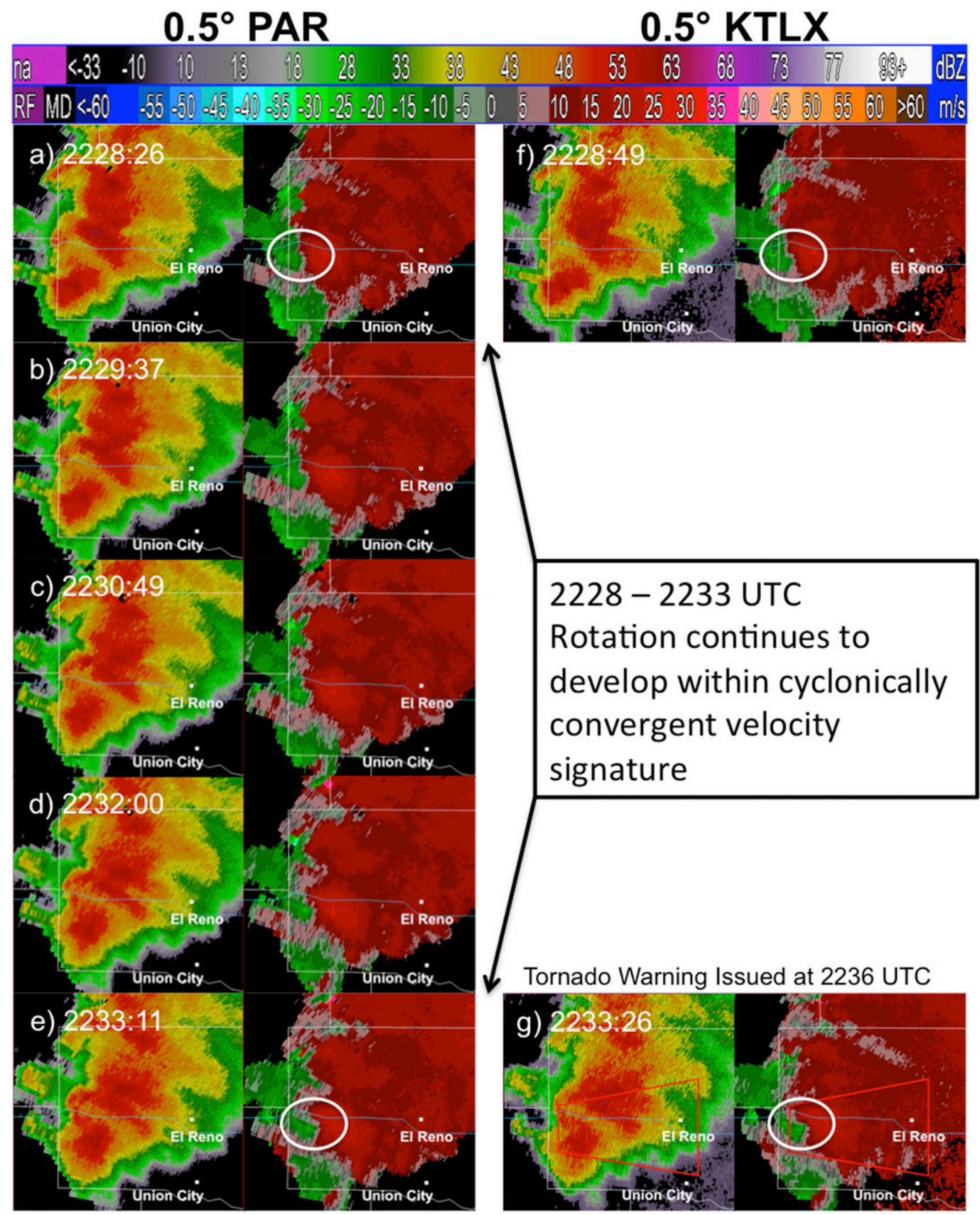

FIG. 6. (a)-(e) PAR and (f),(g) KTLX 0.5 (left) base reflectivity and (right) velocity at (a) 2228:26, (b) 2229:37, (c) 2230:49, (d) 2232:00, (e) 2233:11, (f) 2228:49, and (g) 2233:26 UTC 31 May 2013. Reflectivity (dBZ) and velocity $\left(\mathrm{m} \mathrm{s}^{-1}\right)$ color bars are provided. Distance from PAR to convergent signature is $80 \mathrm{~km}$ and distance from KTLX to convergent signature is $93 \mathrm{~km}$. White circles indicate beginning and ending locations of the feature of interest.

supplemental material). Based on existing supercell conceptual models, this merging process was indicative of both an intensification of low- and midlevel inflow and a possible increasing risk of tornadogenesis (e.g., Bunkers et al. 2006; Lee et al. 2006; Wurman et al. 2007b; Hastings et al. 2012). Indeed, the low- and midlevel inflow increased during this period; this increase was depicted more clearly in PAR data (Figs. 8 and 9). The intensification and dissipation of the first low- and midlevel mesocyclones were also depicted better in the PAR DeltaV trends (Fig. 7). Furthermore, between 2245 and 2249 UTC, the development and intensification of a second midlevel mesocyclone was seen only in PAR's DeltaV trends 
(a)

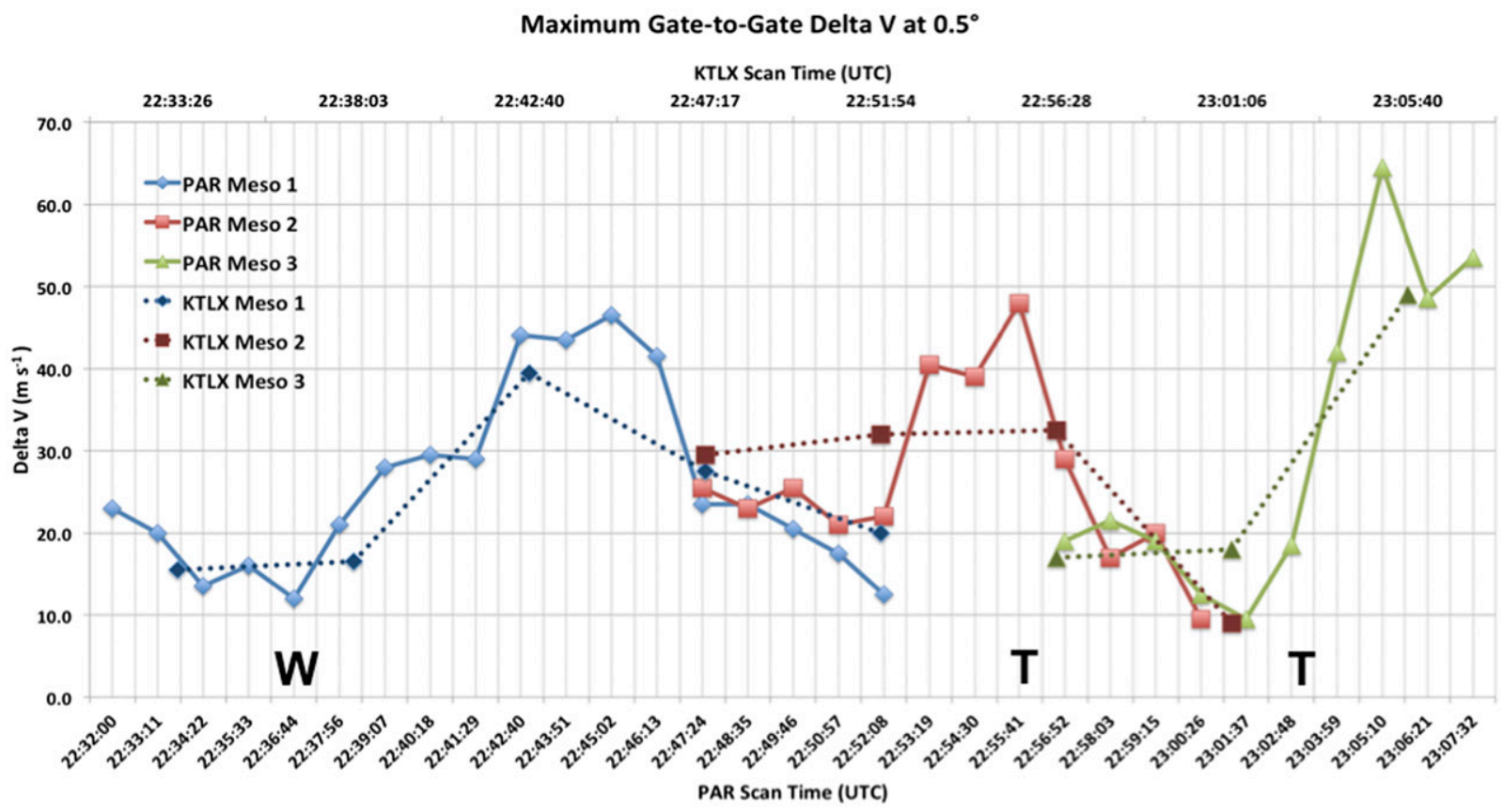

(b)

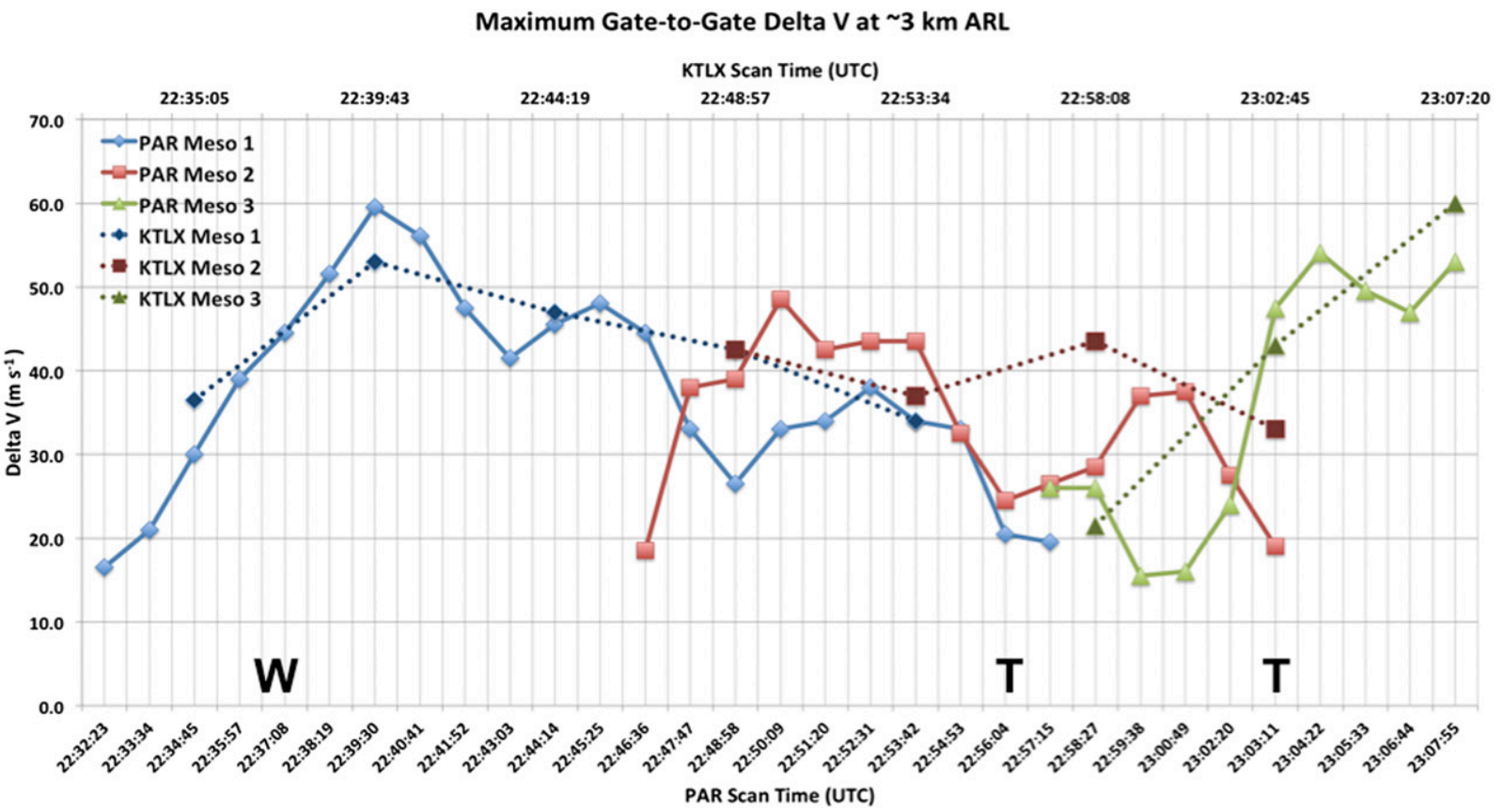

FIG. 7. Evolution of max gate-to-gate DeltaV at (a) $0.5^{\circ}$ and (b) an elevation angle with a height near $3 \mathrm{~km}$ ARL for the first three mesocyclones produced by the El Reno supercell. The solid lines represent PAR data at $2.40^{\circ}$ and the dotted lines represent KTLX data at $1.80^{\circ}$. The boldface letter "W" marks the issuance time of the first tornado warning and the boldface letter "T" marks tornado report times. 
(a) PAR

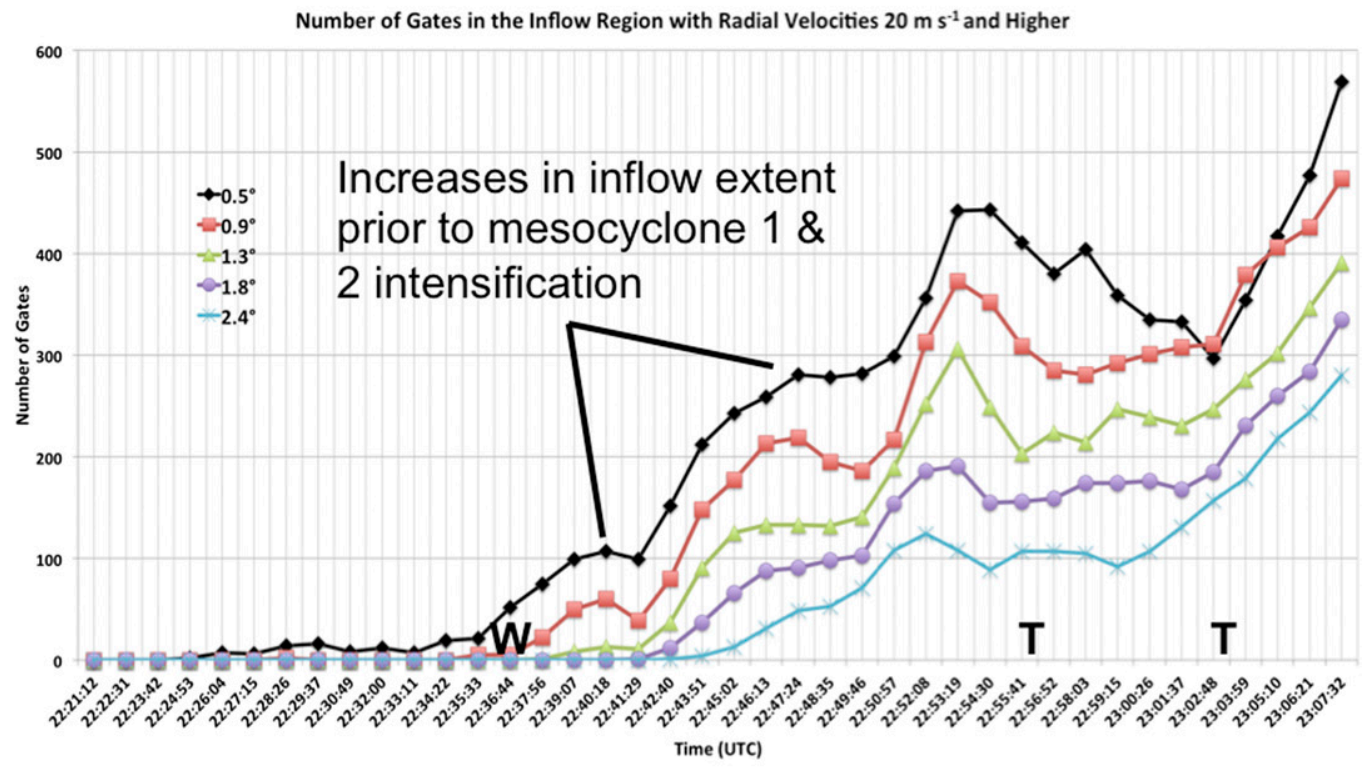

(b) KTLX

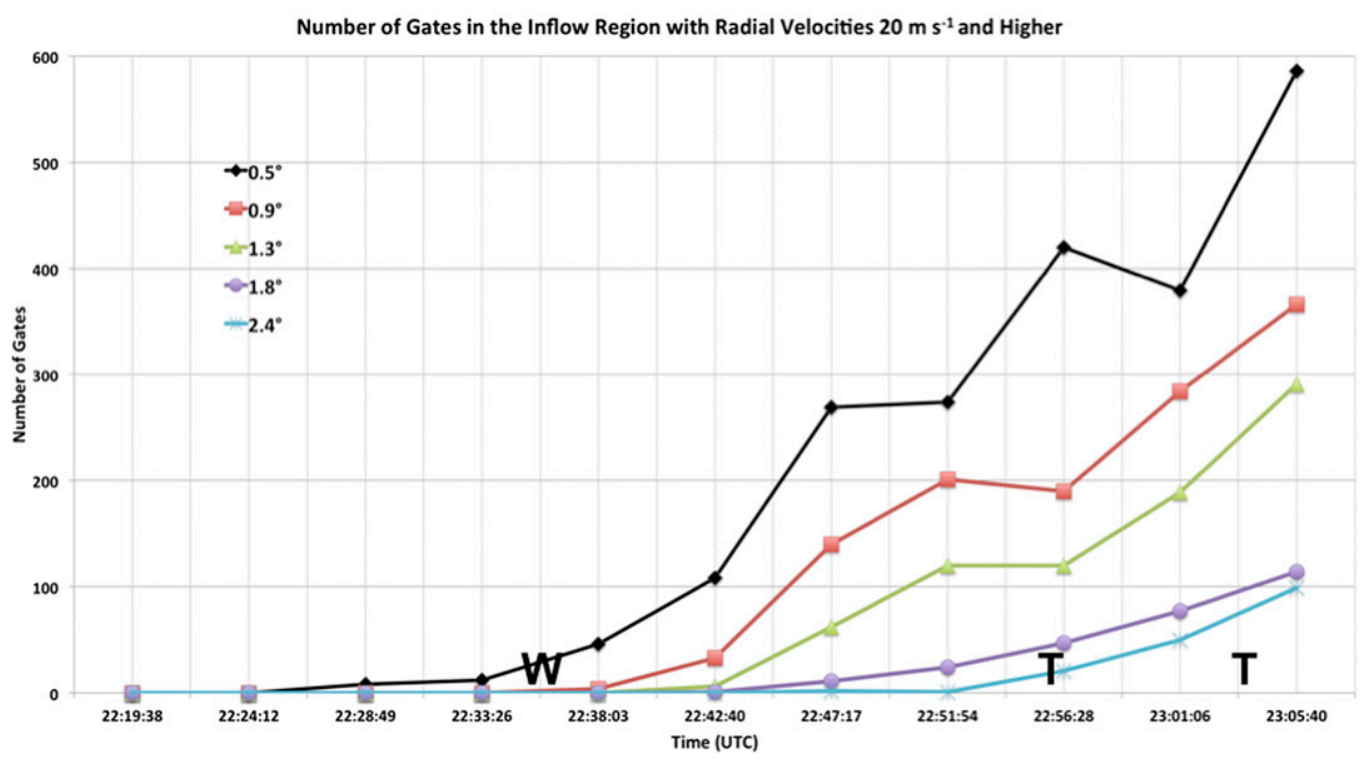

FIG. 8. Evolution of inflow size within the supercell's inflow region at elevation angles of $0.5^{\circ}, 0.9^{\circ}, 1.3^{\circ}, 1.8^{\circ}$, and $2.4^{\circ}$ sampled by (a) PAR and (b) KTLX. The boldface letter "W" marks the issuance time of the first tornado warning and the boldface letter " $\mathrm{T}$ " marks tornado report times.

(Fig. 7b). Shortly thereafter (2251-2256 UTC), PAR's $0.5^{\circ}$ DeltaV trends indicated more clearly than KTLX the development of the low-level mesocyclone (Fig. 7).

The mesocyclones sampled by PAR (Fig. 7a) were each preceded by increases in inflow extent and magnitude (Figs. 8 and 9). In contrast, the mesocyclones sampled by KTLX were preceded by a continuous increase in inflow (Figs. 7-9). Both radars sampled a well-defined BWER aloft, coincident with these developments (not shown). These diagnostic features implied an increase in updraft intensity and, hence, a means for producing vertical vorticity aloft via tilting of horizontal vorticity (e.g., Davies-Jones et al. 2001; Markowski and Richardson 2009).

During the next $10 \mathrm{~min}$ (2255-2305 UTC) two tornadoes formed: the Calumet, Oklahoma, tornado at 


\section{(a) PAR}

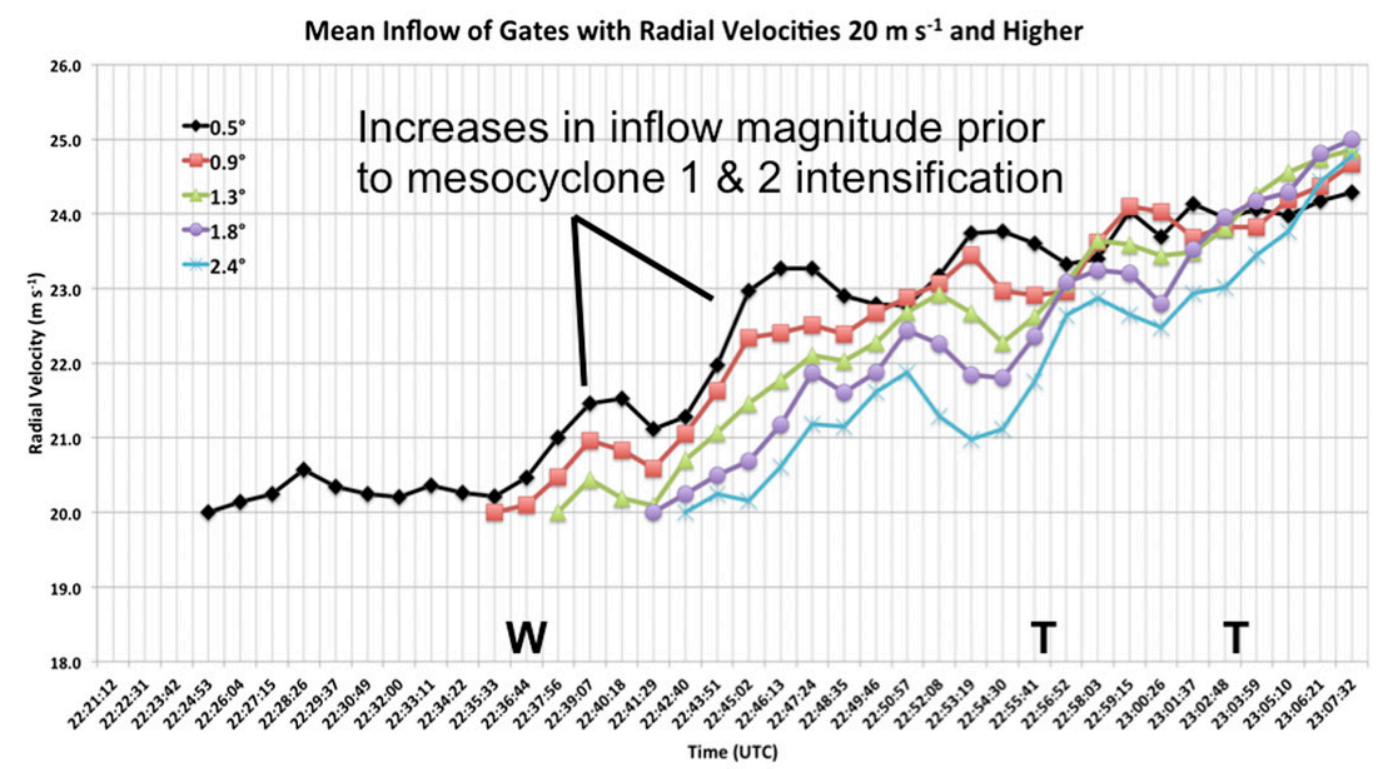

\section{(b) KTLX}

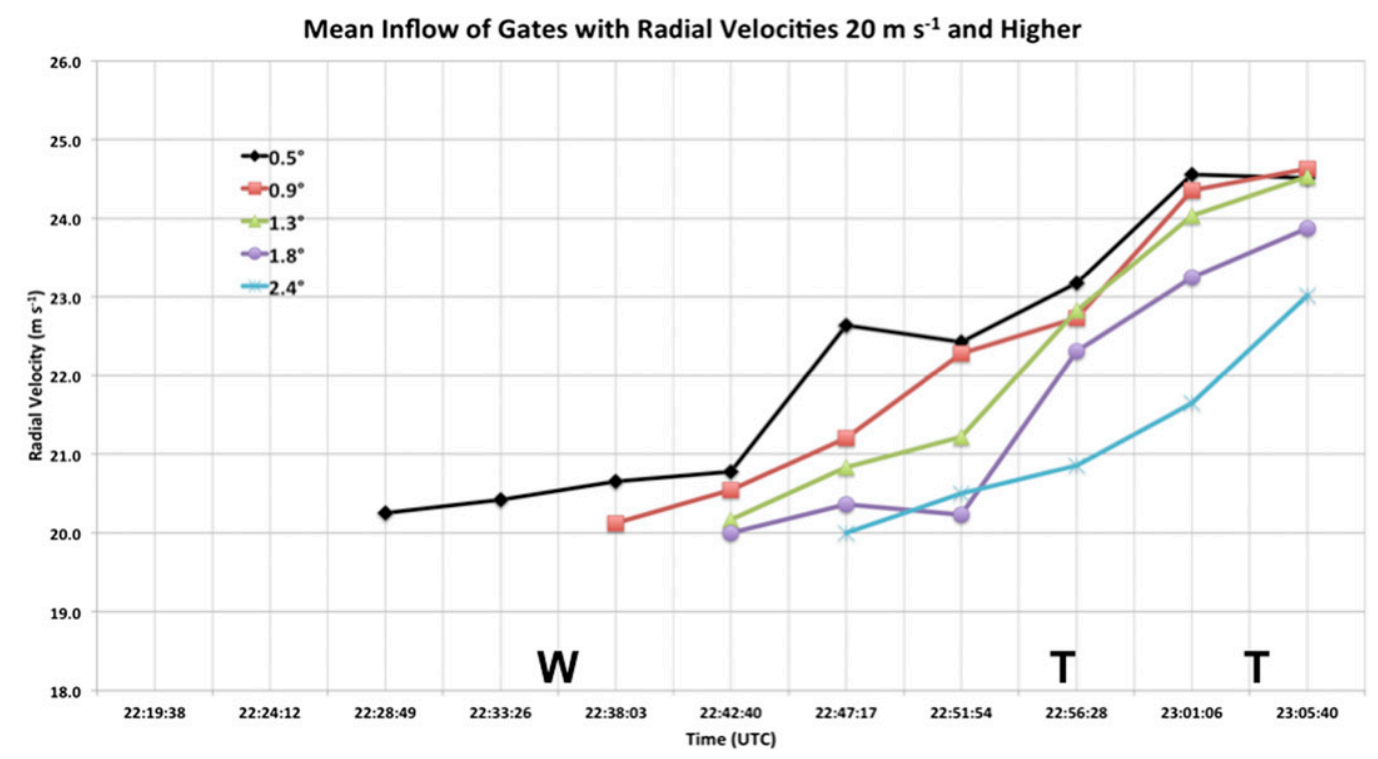

FIG. 9. Evolution of inflow $20 \mathrm{~m} \mathrm{~s}^{-1}$ or higher within the supercell's inflow region at elevation angles of $0.5^{\circ}, 0.9^{\circ}$, $1.3^{\circ}, 1.8^{\circ}$, and $2.4^{\circ}$ sampled by (a) PAR and (b) KTLX. The boldface letter "W" marks the issuance time of the first tornado warning and the boldface letter " $\mathrm{T}$ " marks tornado report times.

2255 UTC (located $\sim 6 \mathrm{mi}$ south of Calumet and $66 \mathrm{~km}$ from PAR), which was 0 on the enhanced Fujita scale (EF0); and the EF3-rated El Reno tornado at 2303 UTC (NCDC 2013). Preceding the EF0-rated Calumet tornado, the development and rapid intensification of a TVS was evident in the $0.5^{\circ} \mathrm{PAR}$ data (Figs. 7a and 11a-e; please also see animation for Fig. 11 in the supplemental material). The development of the TVS seen in the PAR data occurred along with enhanced convergence along the interface of the strong RFD and inflow, and the development of a well-defined inflow notch and tight reflectivity gradient along the supercell's forward flank (e.g., Kulie and Lin 1998; Shabbot and Markowski 2006; see Figs. $11 \mathrm{~b}-\mathrm{d})$. The presence of these diagnostic features suggested the potential for imminent tornadogenesis via 


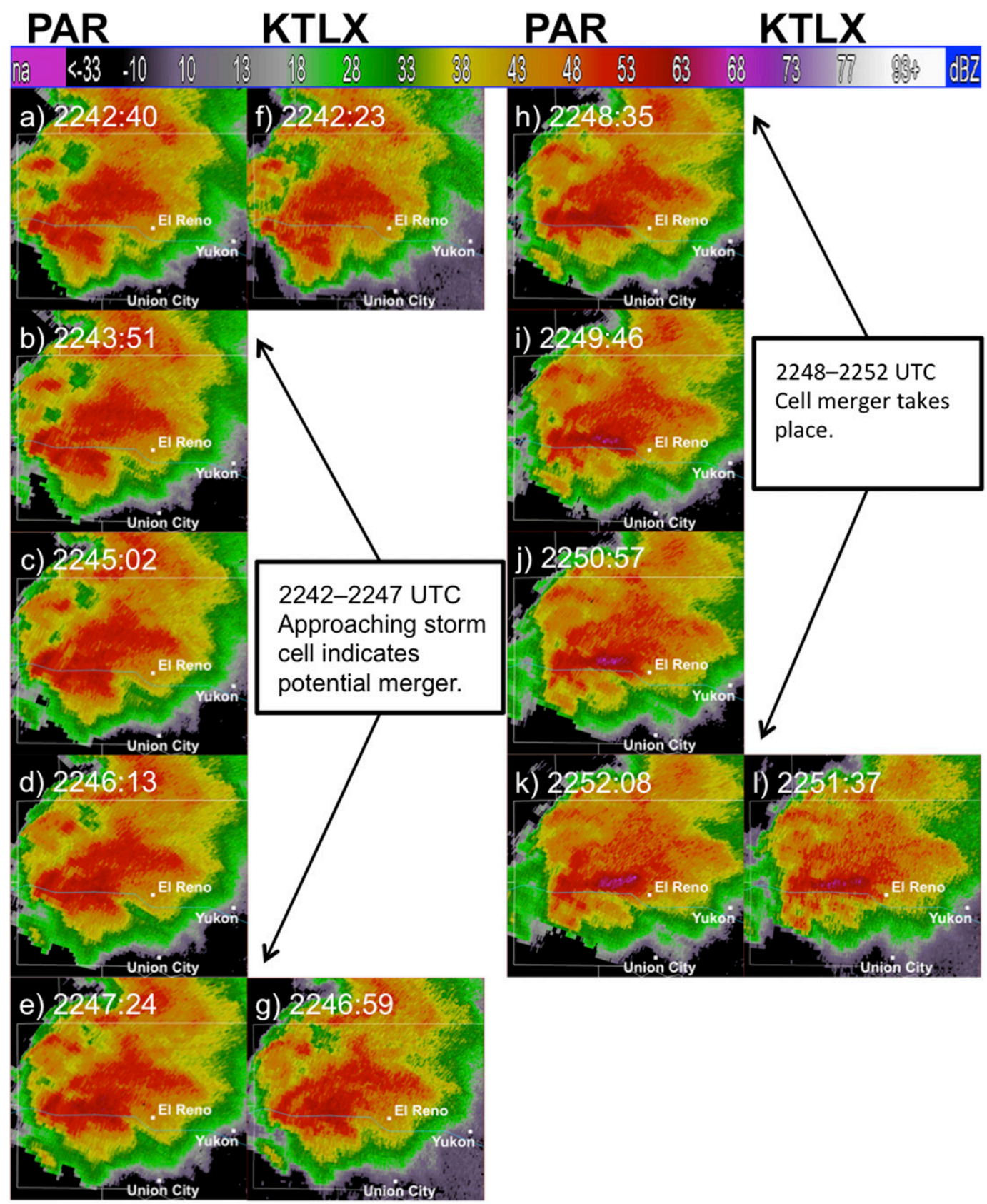

FIG. 10. (a),(b),(c),(d),(e),(h),(i),(j),(k) PAR and (f),(g),(l) KTLX 0.5 base reflectivity at (a) 2242:40, (b) 2243:51, (c) 2245:02, (d) 2246:13, (e) 2247:24, (f) 2242:23, (g) 2246:59, (h) 2248:35, (i) 2249:46, (j) 2250:57, (k) 2252:08, and (l) 2251:37 UTC 31 May 2013. Distance from PAR to southwest storm periphery is $70 \mathrm{~km}$ and distance from KTLX to southwest storm periphery is $85 \mathrm{~km}$. Reflectivity $(\mathrm{dBZ})$ color bar is provided.

the stretching of vertical vorticity that was present at low levels (e.g., Davies Jones et al. 2001). Because this TVS occurred between the 2251 and 2256 UTC KTLX scans (Figs. 7b and 11f,g), the TVS was unobserved during operations.

Prior to the EF3-rated El Reno tornado, the size and magnitude of low- and midlevel (i.e., below $4 \mathrm{~km}$ ARL) inflow began to increase again ( $\sim 2301$ UTC; Figs. 8 and 9), after the second mesocyclone dissipated (Fig. 7). At this time, a strong RFD converging with the intense inflow region of the supercell was seen in both the KTLX and PAR data (Figs. 12a,f). Between 2301 and 2305 UTC, evident in PAR data was the movement of the RFD farther into the inflow; the interface between 


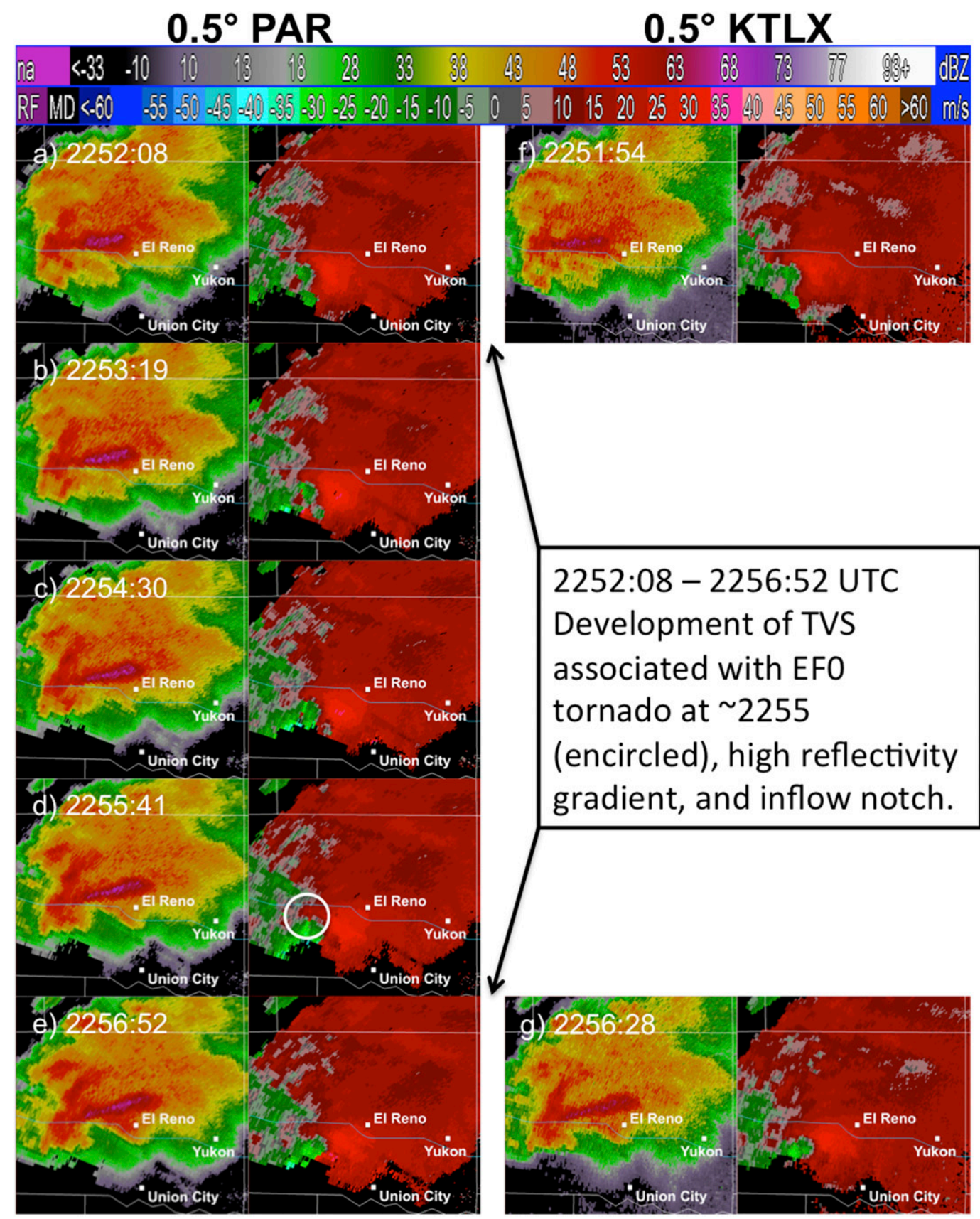

FIG. 11. (a)-(e) PAR and (f),(g) KTLX $0.5^{\circ}$ (left) base reflectivity and (right) velocity at (a) 2252:08, (b) 2253:19, (c) 2254:30, (d) 2255:41, (e) 2256:22, (f) 2251:54, and (g) 2256:28 UTC 31 May 2013. Distance from PAR to highreflectivity gradient is $62 \mathrm{~km}$ and distance from KTLX to high-reflectivity gradient is $76 \mathrm{~km}$. Reflectivity (dBZ) and velocity $\left(\mathrm{m} \mathrm{s}^{-1}\right)$ color bars are provided.

these features became more concentrated, resulting in the transition from a weak cyclonically convergent signature, to an intense and almost purely rotational circulation (Figs. 12b-d; please see animation for this figure in the supplemental material). Here, DeltaV computed from the $0.5^{\circ} \mathrm{PAR}$ data showed this dramatic change in intensity, with an increase from nearly $10 \mathrm{~m} \mathrm{~s}^{-1}$ at 2301:37 UTC to nearly $65 \mathrm{~m} \mathrm{~s}^{-1}$ at $2305: 10$ UTC (Fig. 7a). Unlike the previous two mesocyclones sampled by PAR, this one developed simultaneously at $0.5^{\circ}$ and $2.4^{\circ}$. This simultaneous development of rotation is similar to that reported in mobile radar and modeling 


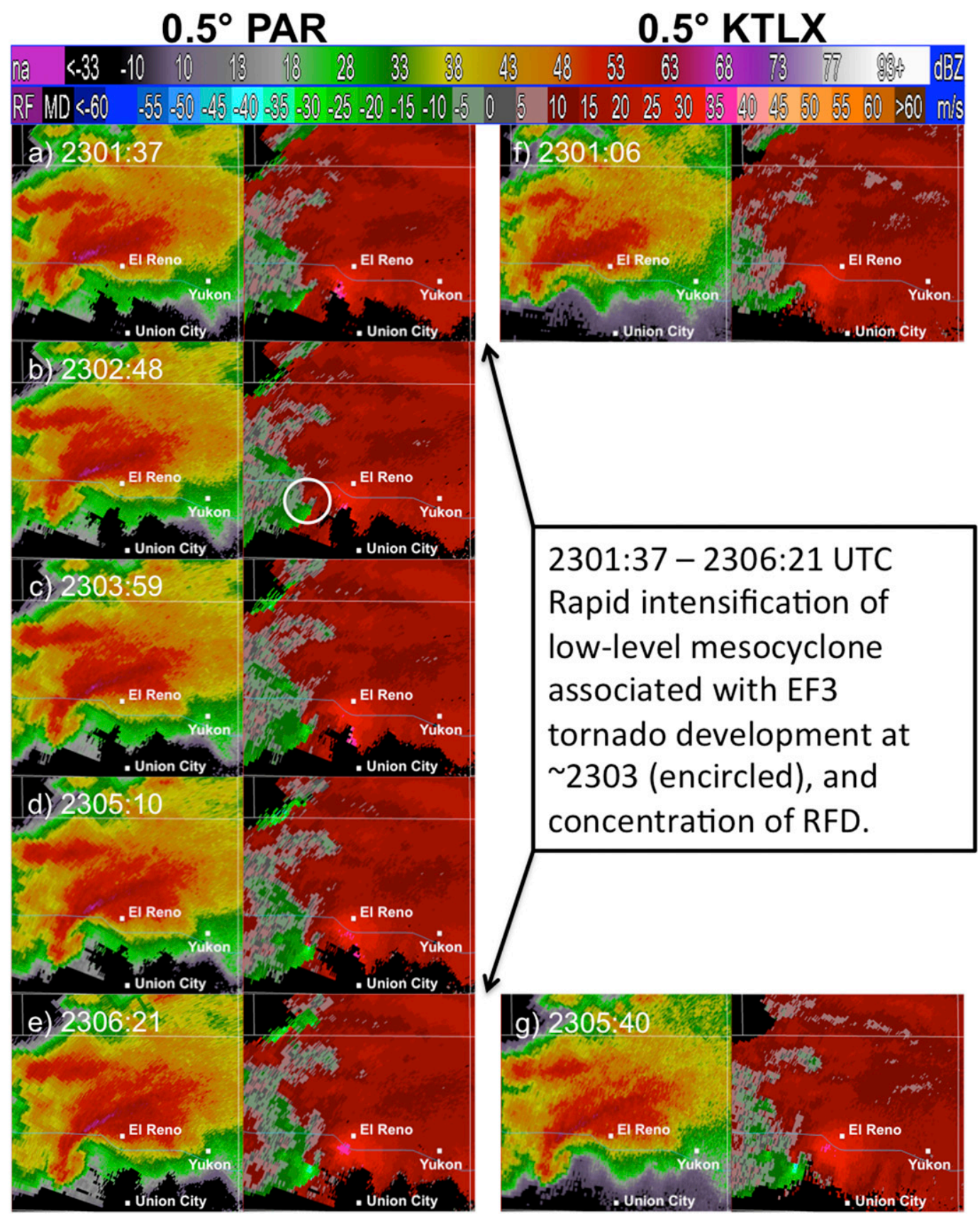

FIG. 12. (a)-(e) PAR and (f),(g) KTLX $0.5^{\circ}$ (left) base reflectivity and (right) velocity at (a) 2301:37, (b) 2302:48, (c) 2303:59, (d) 2305:10, (e) 2306:21, (f) 2301:06, and (g) 2305:40 UTC 31 May 2013. Distance from PAR to velocity couplet is $61 \mathrm{~km}$ and distance from KTLX to velocity couplet is $74 \mathrm{~km}$. Reflectivity $(\mathrm{dBZ})$ and velocity $\left(\mathrm{m} \mathrm{s}^{-1}\right)$ color bars are provided.

studies (e.g., Trapp and Fiedler 1995; French et al. 2013, 2014; Houser et al. 2015). In contrast, the midlevel mesocyclone observed by KTLX developed prior to the lowlevel mesocyclone, which could be interpreted as descent (e.g., Lemon et al. 1978). Rapid-update radar data could therefore improve a forecaster's ability to apply updated tornadogenesis conceptual models. Furthermore, by
2304 UTC a significant TVS was observed by PAR (Fig. 12c) to be nearly coincident with the onset of the El Reno tornado at approximately 2303 UTC (NCDC 2013). The subsequent KTLX scan would take approximately another minute and a half to show this feature (Fig. 12g). Thus, KTLX failed to depict the rapid evolution and intensification of the low-level mesocyclone, and 
provided less timely information regarding the onset of the El Reno tornado indicated by the TVS. In this case, the rapid-update data provided by PAR made it easier to observe and interpret the evolution of key features in tornadogenesis, such as the RFD and TVS, which in operations could lead to increased confidence in the existence of a strong tornado near El Reno (Fig. 12).

\section{c. Rapid changes in motion of circulation and tornado}

An accurate fix on the circulation and its expected motion are critical in shaping warning polygons and providing timely location information once a persistent low-level mesocyclone and its embedded TVS have formed. The tornado that affected areas between El Reno and Union City displayed erratic changes in motion and forward speed throughout its life (Snyder and Bluestein 2014; Wurman et al. 2014). From 2319 to 2324 UTC, the tornado made an abrupt northward turn, and PAR imagery clearly showed this progression (Figs. 13a-e; please see animation for this figure in the supplemental material). KTLX, on the other hand, captured the circulation just before the tornado began its northward turn, such that this change in motion was not seen until the following volume scan at 2324 UTC (Figs. 13f,g). By 2328 UTC, the northward motion of the tornadic circulation began to decrease. At this time, a tornado emergency was issued for Yukon, Oklahoma, and Oklahoma City as this tornadic supercell was approaching the western outskirts of this metropolitan area. Between 2328 and 2333 UTC the stalling of the tornadic circulation along Interstate 40 was well sampled by PAR (Figs. 14b-d), whereas KTLX volume scans were spaced such that evidence of the stalling tornadic circulation was delayed (Figs. 14f,g; please see animation for this figure in the supplemental material). As a result, during operations the tornado appeared as though it might continue moving north after 2328 UTC, and potentially approach the northern edge of the newly issued tornado emergency (Fig. 14). Had PAR data been available, it would have been clear that the tornado had become nearly stationary (Figs. 14b-d). In addition, the 1-min frequency in PAR scans would have allowed for more accurate estimated tornado locations and expected motion in updates to existing warnings. During tornado-warning operations, knowing when a tornado has shifted direction or speed is equally important as knowing when the tornado has stopped moving altogether. These changes were not sampled well by KTLX.

\section{d. Supercell inflow cutoff by surging RFD}

KTLX reflectivity morphology during the early stages of the El Reno supercell suggested it might remain a dominant isolated supercell as it moved into Oklahoma City. As early as 2314 UTC, it became apparent that additional supercells were developing in close proximity to the El Reno storm (Fig. 15a). By 2342 UTC, PAR and KTLX displayed a complex scenario with training supercells from near Yukon to west of El Reno (Fig. 15b). At this time, the El Reno tornado had fully occluded and was ongoing along Interstate 40 west of Yukon (Figs. 16a,f). The forecast challenge was determining whether a second tornado would develop to the southeast of the occluded circulation within the Oklahoma City limits, where another strong mesocyclone was developing. During the next few minutes (2343-2347 UTC), the onset of a strong surging RFD was sampled earlier by PAR than KTLX (Fig. 16; please see animation for this figure in the supplemental material), as the tornadic supercell approached the Oklahoma City metropolitan area. The presence of this surging RFD suggested that the storm was becoming outflow dominant, resulting in a temporary decline in the likelihood of a violent tornado (e.g., Markowski et al. 2002). After 2347 UTC, a surging RFD could be seen in both PAR and KTLX data (not shown). PAR continued to reveal a clearer picture of the RFD evolution than KTLX, but the impact of rapid-scan data diminished because the RFD was not expanding as quickly.

\section{Conclusions}

In this study, the forecaster who issued tornado warnings for the 31 May 2013 EF3-rated El Reno tornadic supercell evaluated the ability to observe storm evolution significant to his supercell tornadogenesis conceptual model using 70-s PAR and 4.58-min KTLX data. In this case, the high temporal-resolution PAR data proved most advantageous compared to KTLX in the depiction of the following:

- cycles of low- and midlevel mesocyclones and associated changes in the extent and magnitude of storm inflow,

- rapid intensification of the low-level mesocyclone and embedded TVS preceding the EF0-rated Calumet and EF3-rated El Reno tornadoes, and

- abrupt, short-term changes in the motion of the tornado circulation and more precision in its location.

In this study, computed trends of mesocyclone and inflow intensity (Figs. 7-9) matched the forecaster's assessment of associated evolution seen in the KTLX and PAR data. This result suggests that when the use of such rapid-scan data becomes a reality, providing computed trends to forecasters in real time may aid in 


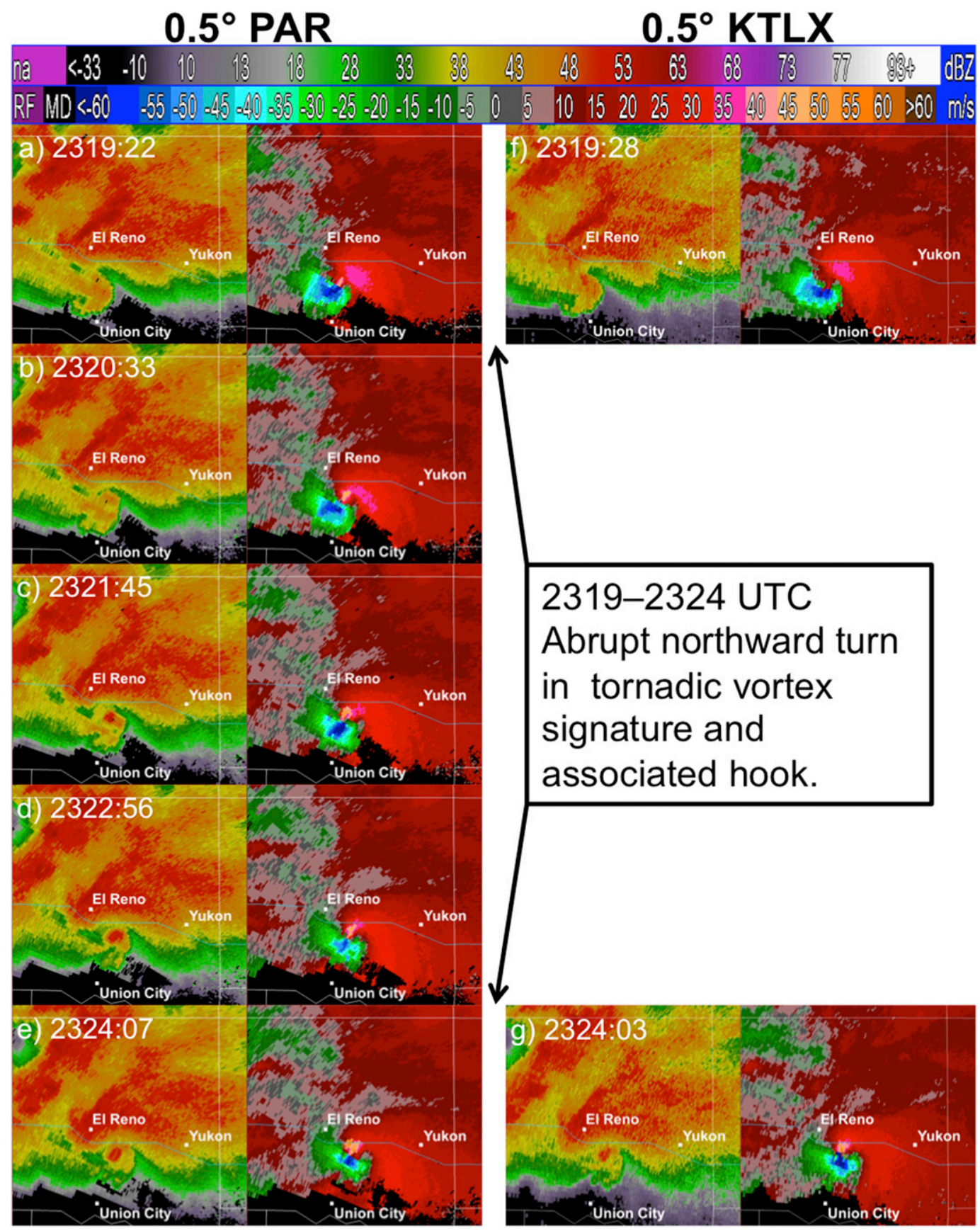

FIG. 13. (a)-(e) PAR and (f),(g) KTLX $0.5^{\circ}$ (left) base reflectivity and (right) velocity at (a) 2319:22, (b) 2320:33, (c) 2321:45, (d) 2322:56, (e) 2324:07, (f) 2319:28, and (g) 2324:03 UTC 31 May 2013. Distance from PAR to velocity couplet is $49 \mathrm{~km}$ and distance from KTLX to velocity couplet is $61 \mathrm{~km}$. Reflectivity $(\mathrm{dBZ})$ and velocity $\left(\mathrm{m} \mathrm{s}^{-1}\right)$ color bars are provided.

their application of tornadogenesis conceptual models and result in increased confidence throughout the warning process.

These findings add to the growing body of knowledge regarding the potential impacts of radar sampling time on the depiction of forecaster-employed conceptual models
(Heinselman et al. 2012, 2015; Bowden et al. 2015). We initially expected that radar data might be less beneficial during a strong tornado case because environmental cues were so supportive of tornadoes (see section 3). However, in this case the improved depiction of storm evolution provided by PAR was relevant to radar-based forecast 


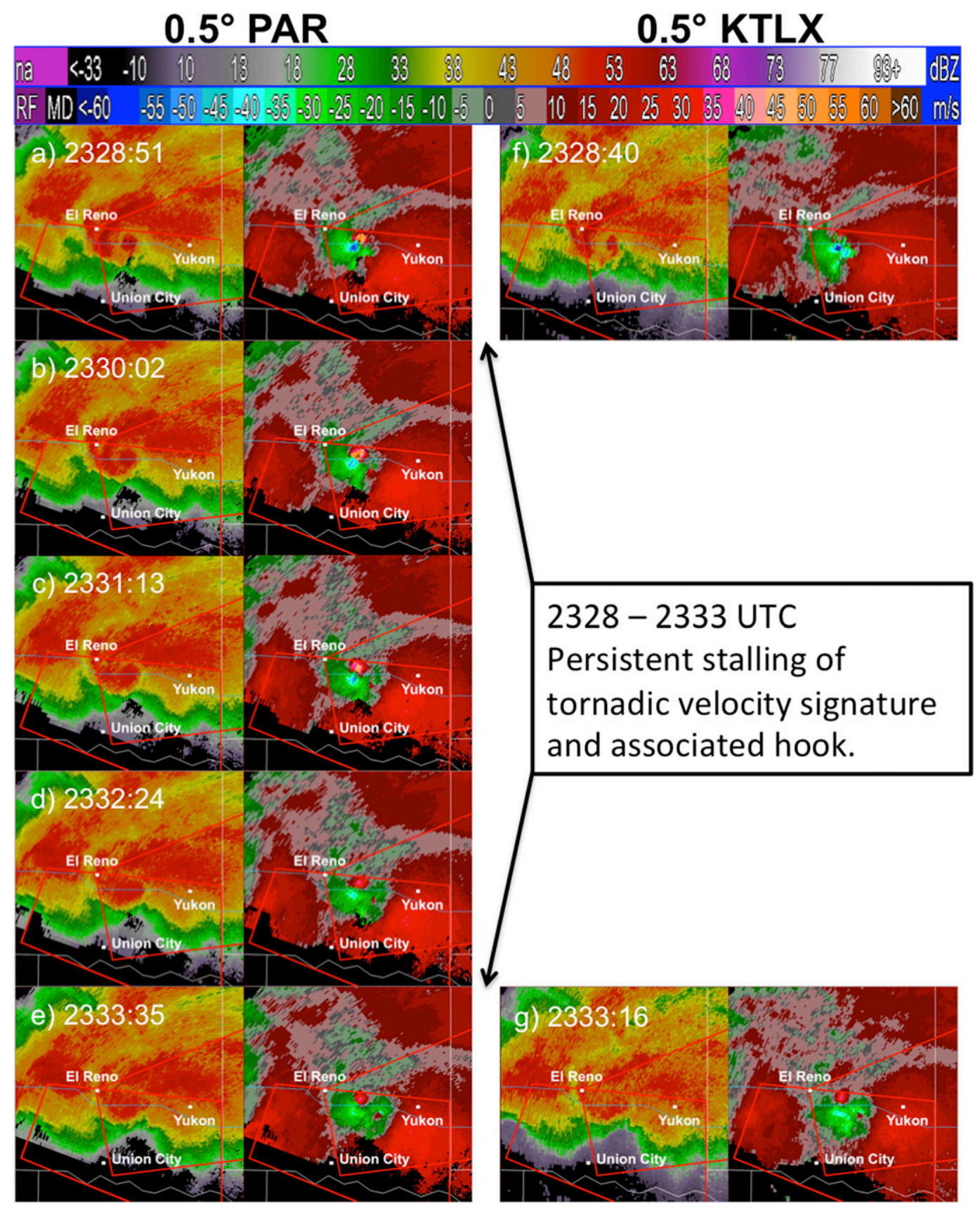

FIG. 14. (a)-(e) PAR and (f),(g) KTLX $0.5^{\circ}$ (left) base reflectivity and (right) velocity at (a) 2328:51, (b) 2330:02, (c) 2331:13, (d) 2332:24, (e) 2333:35, (f) 2328:40, and (g) 2333:16 UTC 31 May 2013. Distance from PAR to velocity couplet is $48 \mathrm{~km}$ and distance from KTLX to velocity couplet is $58 \mathrm{~km}$. Reflectivity $(\mathrm{dBZ})$ and velocity $\left(\mathrm{m} \mathrm{s}^{-1}\right)$ color bars are provided. The red lines enclose the second tornado warning (westernmost polygon) and first tornado emergency issued on the El Reno supercell that was valid at these times.

challenges recalled by the forecaster. Importantly, these examples indicate that the use of PAR data in operations could improve a forecaster's ability to monitor and understand storm evolution during strong tornado events. In turn, this would allow the forecaster to better communicate threat information to the general public, as well as responders to natural disasters (e.g., emergency managers, police, Red Cross workers, fire fighters, etc.), especially in terms of a tornado's occurrence, location, and motion. Furthermore, 
KTLX

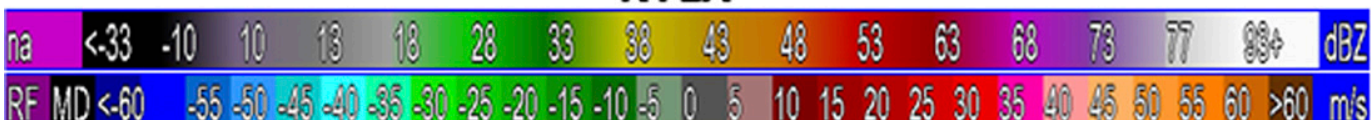
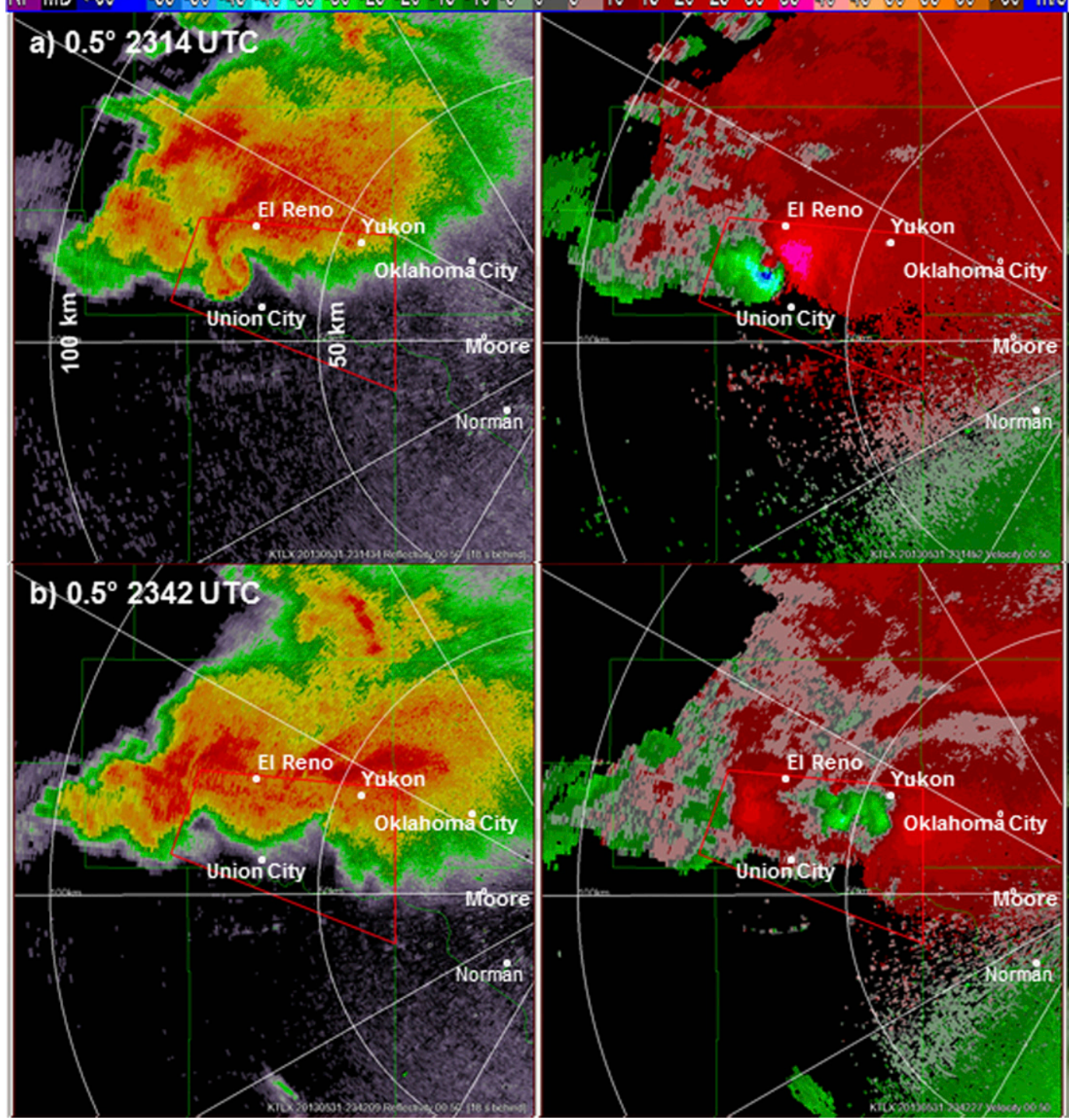

FIG. 15. KTLX $0.5^{\circ}$ (left) base reflectivity and (right) velocity at (a) 2314 and (b) 2342 UTC 31 May 2013. Reflectivity $(\mathrm{dBZ})$ and velocity $\left(\mathrm{m} \mathrm{s}^{-1}\right)$ color bars are provided. The white rings are displayed at $50-\mathrm{km}$ increments. The red line encloses the second tornado warning issued on the El Reno supercell that was valid at these times.

such data can enhance a forecaster's ability to apply aspects of updated tornadogenesis conceptual models that are undersampled by the WSR-88D, including the simultaneous vertical development of a tornadic mesocyclone.

Future experiments need to explore whether this study's findings would be applicable to other highimpact tornado events in central Oklahoma. Given the strong matching of computed trends to the forecaster's interpretation of the radar data, it is possible that such a product may aid a forecaster's situational awareness and potentially help to minimize data overload during challenging situations, such as multiple tornadic supercell events. The addition of such products to future experiments could determine their usefulness. Ideally, these studies would take place in an operational office where forecasters' abilities to apply conceptual models, performance, and work processes could be tracked over time to inform the development of the next generation of radar technology. 


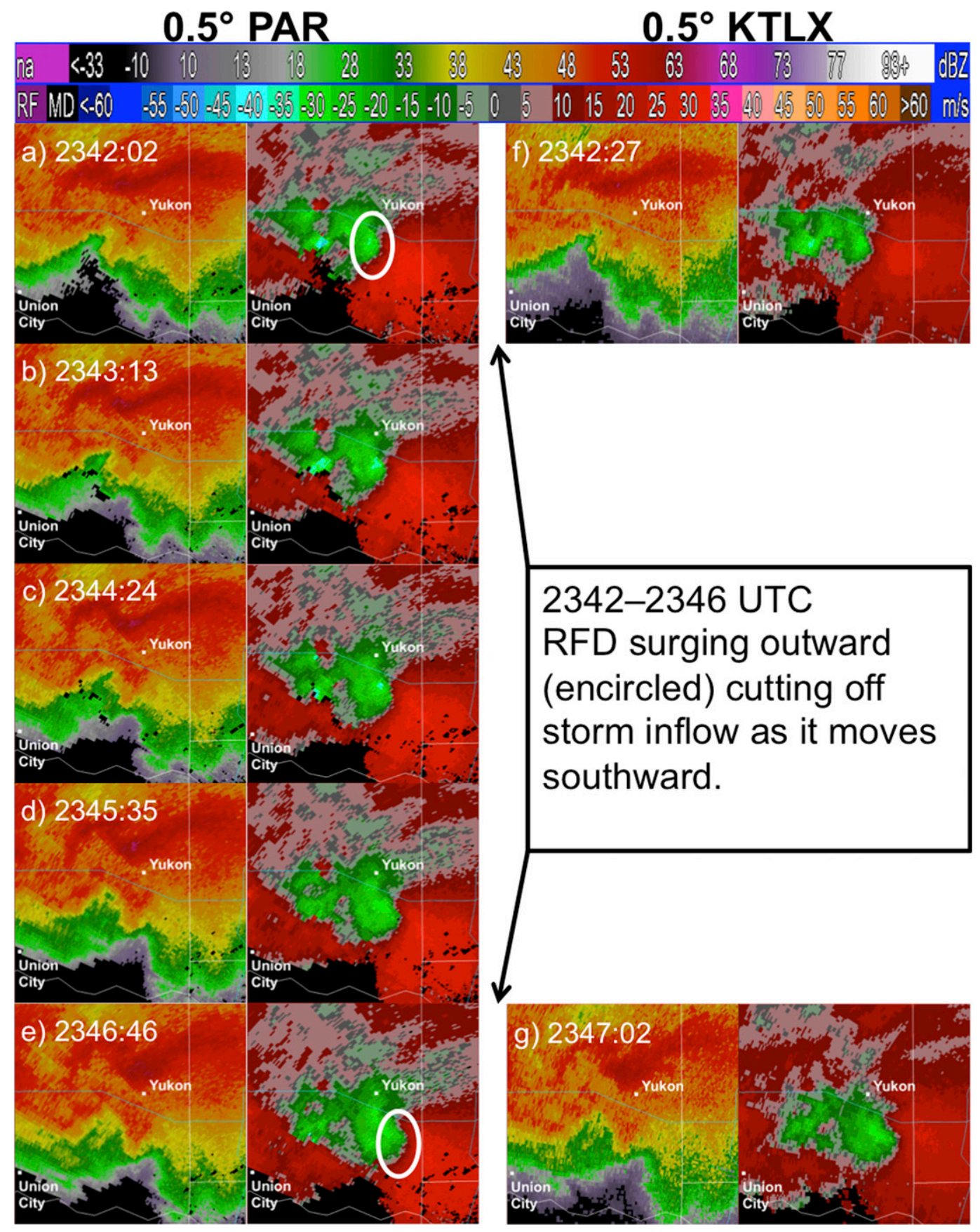

FIG. 16. (a)-(e) PAR and (f),(g) KTLX $0.5^{\circ}$ (left) base reflectivity and (right) velocity at (a) 2342:02, (b) 2343:13, (c) 2344:24, (d) 2345:35, (e) 2346:46, (f) 2342:27, and (g) 2347:02 UTC 31 May 2013. Distance from PAR to RFD is $34 \mathrm{~km}$ and distance from KTLX to RFD is $44 \mathrm{~km}$. Reflectivity ( $\mathrm{dBZ})$ and velocity $\left(\mathrm{m} \mathrm{s}^{-1}\right)$ color bars are provided.

Acknowledgments. The authors thank Jeff Brogden, Karen Cooper, and Robert Toomey for their expertise with WDSSII and SOLO, Patrick Skinner for helping with radar data editing, Katie Bowden, Rodger Brown, Kurt Hondl, and Doug Speheger for their internal reviews of the manuscript, and Emma Kuster for assistance with
Python. We also thank two anonymous reviewers who helped us refine and clarify many elements of the manuscript. Funding for the lead author was provided by NOAA/Office of Oceanic and Atmospheric Research under NOAA-University of Oklahoma Cooperative Agreement NA11OAR4320072, U.S. Department of Commerce. 


\section{REFERENCES}

Adlerman, E. J., K. K. Droegemeier, and R. Davies-Jones, 1999: A numerical simulation of cyclic mesocyclogenesis. J. Atmos. Sci., 56, 2045-2069, doi:10.1175/1520-0469(1999)056<2045: ANSOCM $>2.0 . C O ; 2$.

Andra, D. L., E. M. Quoetone, and W. F. Bunting, 2002: Warning decision making: The relative roles of conceptual models, technology, strategy, and forecaster expertise on 3 May 1999. Wea. Forecasting, 17, 559-566, doi:10.1175/1520-0434(2002)017<0559: WDMTRR $>2.0 . \mathrm{CO} ; 2$.

Boustead, J. M., B. E. Mayes, W. Gargan, J. L. Leighton, G. Phillips, and P. N. Schumacher, 2013: Discriminating environmental conditions for significant warm sector and boundary tornadoes in parts of the Great Plains. Wea. Forecasting, 28, 1498-1523, doi:10.1175/WAF-D-12-00102.1.

Bowden, K. A., P. L. Heinselman, D. M. Kingfield, and R. P. Thomas, 2015: Impacts of phased-array radar data on forecaster performance during severe hail and wind events. Wea. Forecasting, 30, 389-404, doi:10.1175/WAF-D-14-00101.1.

Brandes, E. A., 1978: Mesocyclone evolution and tornadogenesis: Some observations. Mon. Wea. Rev., 106, 995-1011, doi:10.1175/ 1520-0493(1978)106<0995:MEATSO > 2.0.CO;2.

- 1984: Vertical vorticity generation and mesocyclone sustenance in tornadic thunderstorms: The observational evidence. Mon. Wea. Rev., 112, 2253-2269, doi:10.1175/1520-0493(1984)112<2253: VVGAMS $>2.0 . \mathrm{CO} ; 2$.

Branick, M., 1996: A comprehensive glossary of weather terms for storm spotters. NOAA Tech. Memo. NWS SR-145, 2nd ed., 49 pp. [Available online at: http://www.srh.noaa.gov/oun/ ?n= spotterglossary].

Brooks, H. E., C. A. Doswell III, and R. Davies-Jones, 1993: Environmental helicity and the maintenance and evolution of low-level mesocyclones. The Tornado: Its Structure, Dynamics, Prediction, and Hazards, Geophys. Monogr., Vol. 79, Amer. Geophys. Union, 97-104.

,-- , and R. B. Wilhelmson, 1994: The role of midtropospheric winds in the evolution and maintenance of low-level mesocyclones. Mon. Wea. Rev., 122, 126-136, doi:10.1175/ 1520-0493(1994)122<0126:TROMWI >2.0.CO;2.

Brown, R. A., L. R. Lemon, and D. W. Burgess, 1978: Tornado detection by pulsed Doppler radar. Mon. Wea. Rev., 106, 29-38, doi:10.1175/1520-0493(1978)106<0029:TDBPDR >2.0.CO;2.

—, B. A. Flickinger, E. Forren, D. M. Schultz, D. Sirmans, P. L. Spencer, V. T. Wood, and C. L. Ziegler, 2005a: Improved detection of severe storms using experimental fine-resolution WSR88D measurements. Wea. Forecasting, 20, 3-14, doi:10.1175/ WAF-832.1.

—, R. M. Steadham, B. A. Flickinger, R. R. Lee, D. Sirmans, and V. T. Wood, 2005b: New WSR-88D volume coverage pattern 12: Results of field tests. Wea. Forecasting, 20, 385-393, doi:10.1175/WAF848.1.

Bunkers, M. J., M. R. Hjelmfelt, and P. L. Smith, 2006: An observational examination of long-lived supercells. Part I: Characteristics, evolution, and demise. Wea. Forecasting, 21, 673-688, doi:10.1175/WAF949.1.

Burgess, D. W., L. R. Lemon, and R. A. Brown, 1975: Tornado characteristics revealed by Doppler radar. Geophys. Res. Lett., 2, 183-184, doi:10.1029/GL002i005p00183.

, K. E. Wilk, J. D. Bonewitz, K. M. Glover, D. W. Holmes, and J. Hinkelman, 1979: Doppler radar: The Joint Doppler Operational Project. Weatherwise, 32, 72-75, doi:10.1080/ 00431672.1979 .9931867$.
Chrisman, J. N., 2009: Automated volume scan evaluation and termination (AVSET): A simple technique to achieve faster volume scan updates for the WSR-88D. Preprints, 34th Conf. on Radar Meteorology, Williamsburg, VA, Amer. Meteor. Soc., P4.4. [Available online at http://ams.confex.com/ams/ pdfpapers/155324.pdf.]

Crum, T. D., and R. L. Alberty, 1993: The WSR-88D and the WSR-88D Operational Support Facility. Bull. Amer. Meteor. Soc., 74, 1669-1687, doi:10.1175/1520-0477(1993)074<1669: TWATWO $>2.0 . \mathrm{CO} ; 2$.

_ S. D. Smith, J. N. Chrisman, R. E. Saffle, R. W. Hall, and R. J. Vogt, 2013: WSR-88D radar projects - Update 2013. Proc. 29th Conf. on Environmental Information Processing Technologies, Austin, TX, Amer. Meteor. Soc., 8.1. [Available online at https://ams.confex.com/ams/93Annual/webprogram/ Paper221461.html.]

Davies-Jones, R. P., 2008: Can a descending rain curtain in a supercell instigate tornadogenesis barotropically? J. Atmos. Sci., 65, 2469-2497, doi:10.1175/2007JAS2516.1.

— R. J. Trapp, and H. B. Bluestein, 2001: Tornadoes and tornadic storms. Severe Convective Storms, Meteor. Monogr., No. 50, Amer. Meteor. Soc., 167-221.

Doswell, C. A., III, and D. W. Burgess, 1993: Tornadoes and tornadic storms: A review of conceptual models. The Tornado: Its Structure, Dynamics, Prediction, and Hazards, Geophys. Monogr., Vol. 79, Amer. Geophys. Union, 161-172.

Dowell, D. C., and H. B. Bluestein, 2002: The 8 June 1995 McLean, Texas, storm. Part I: Observations of cyclic tornadogenesis. Mon. Wea. Rev., 130, 2626-2648, doi:10.1175/1520-0493(2002)130<2626: TJMTSP $>2.0 . \mathrm{CO} ; 2$.

Dunn, L. B., 1990: Two examples of operational tornado warnings using Doppler radar data. Bull. Amer. Meteor. Soc., 71, 145-153, doi:10.1175/1520-0477(1990)071<0145: TEOOTW $>2.0 . \mathrm{CO} ; 2$.

Emersic, C., P. L. Heinselman, D. R. MacGorman, and E. C. Bruning, 2011: Lightning activity in a hail-producing storm observed with phased-array radar. Mon. Wea. Rev., 139, 1809 1825, doi:10.1175/2010MWR3574.1.

Esterheld, J. M., and D. J. Guiliano, 2008: Discriminating between tornadic and non-tornadic supercells: A new hodograph technique. Electron. J. Severe Storms Meteor., 3 (2). [Available online at http:// www.ejssm.org/ojs/index.php/ejssm/article/viewArticle/33.]

Forsyth, D. E., and Coauthors, 2005: The National Weather Radar Testbed (phased array). Preprints, 32nd Conf. on Radar Meteorology, Albuquerque, NM, Amer. Meteor. Soc., 12R.3. [Available online at https://ams.confex.com/ams/pdfpapers/96377.pdf.]

French, M. M., H. B. Bluestein, I. PopStefanija, C. A. Baldi, and R. T. Bluth, 2013: Reexamining the vertical development of tornadic vortex signatures in supercells. Mon. Wea. Rev., 141, 4576-4601, doi:10.1175/MWR-D-12-00315.1.

,,$---\longrightarrow$, and - , 2014: Mobile, phased-array, Doppler radar observations of tornadoes at X band. Mon. Wea. Rev., 142, 1010-1036, doi:10.1175/MWR-D-13-00101.1.

Hahn, B. B., E. Rall, and D. W. Klinger, 2003: Cognitive task analysis of the warning forecaster task. Rep. Klein Associates Rep. RA1330-02-SE-0280, 26 pp. [Available online at http:// www.wdtb.noaa.gov/modules/CTA/Final123102rev030108.pdf.]

Hastings, R. M., Y. P. Richardson, P. Markowski, J. Wurman, and C. C. Weiss, 2012: Mergers in supercell environments. Part 1: Conceptual models of mechanisms governing merger outcomes. 26th Conf. on Severe Local Storms, Nashville, TN, Amer. Meteor. Soc., 11B6. [Available online at https://ams. confex.com/ams/26SLS/webprogram/Paper212519.html.] 
Heinselman, P. L., D. L. Priegnitz, K. L. Manross, T. M. Smith, and R. W. Adams, 2008: Rapid sampling of severe storms by the National Weather Radar Testbed Phased Array Radar. Wea. Forecasting, 23, 808-824, doi:10.1175/ 2008WAF2007071.1.

— D. S. LaDue, and H. Lazrus, 2012: Exploring impacts of rapid-scan radar data on NWS warning decisions. Wea. Forecasting, 27, 1031-1044, doi:10.1175/WAF-D-11-00145.1.

_ _ _ D. M. Kingfield, and R. Hoffman, 2015: Tornado warning decisions using phased-array radar data. Wea. Forecasting, 30, 57-78, doi:10.1175/WAF-D-14-00042.1.

Houser, J. L., H. B. Bluestein, and J. C. Snyder, 2015: Rapid-scan, polarimetric, Doppler-radar observations of tornadogenesis and tornado dissipation in a tornadic supercell: The "El Reno, Oklahoma" storm of 24 May 2011. Mon. Wea. Rev., doi:10.1175/MWR-D-14-00253.1, in press.

Johns, R. H., and C. A. Doswell III, 1992: Severe local storms forecasting. Wea. Forecasting, 7, 588-612, doi:10.1175/ 1520-0434(1992)007<0588:SLSF $>2.0 . \mathrm{CO} ; 2$.

Kerr, B. W., and G. L. Darkow, 1996: Storm-relative winds and helicity in the tornadic thunderstorm environment. Wea. Forecasting, 11, 489-505, doi:10.1175/1520-0434(1996)011<0489: SRWAHI $>2.0 . \mathrm{CO} ; 2$.

Klemp, J. B., and R. Rotunno, 1983: A study of the tornadic region within a supercell thunderstorm. J. Atmos. Sci., 40, 359-377, doi:10.1175/1520-0469(1983)040<0359: ASOTTR $>2.0 . \mathrm{CO} ; 2$.

Kosiba, K., J. Wurman, Y. Richardson, P. Markowski, P. Robinson, and J. Marquis, 2013: Genesis of the Goshen County, Wyoming, tornado on 5 June 2009 during VORTEX2. Mon Wea. Rev., 141, 1157-1181, doi:10.1175/MWR-D-12-00056.1.

Kulie, M. S., and Y.-L. Lin, 1998: The structure and evolution of a numerically simulated high-precipitation supercell thunderstorm. Mon. Wea. Rev., 126, 2090-2116, doi:10.1175/ 1520-0493(1998)126<2090:TSAEOA > 2.0.CO;2.

LaDue, D. S., P. L. Heinselman, and J. F. Newman, 2010: Strengths and limitations of current radar systems for two stakeholder groups in the southern plains. Bull. Amer. Meteor. Soc., 91, 899-910, doi:10.1175/2009BAMS2830.1.

Lee, B. D., B. F. Jewett, and R. B. Wilhelmson, 2006: The 19 April 1996 Illinois tornado outbreak. Part II: Cell mergers and associated tornado incidence. Wea. Forecasting, 21, 449-464, doi:10.1175/WAF943.1.

Lemon, L. R., D. W. Burgess, and R. A. Brown, 1978: Tornadic storm airflow and morphology derived from single-Doppler radar measurements. Mon. Wea. Rev., 106, 48-61, doi:10.1175/ 1520-0493(1978)106<0048:TSAAMD > 2.0.CO;2.

Lindley, T., and G. Morgan, 2004: The Pecos County, Texas hail storms of 10 May 2002: A null tornado event from a warning decision perspective. Electron. J. Oper. Meteor., 5 (1). [Available online at http://www.nwas.org/ej/2004-EJ1/.]

Markowski, P. M., and Y. P. Richardson, 2009: Tornadogenesis: Our current understanding, forecasting considerations, and questions to guide future research. Atmos. Res., 93, 3-10, doi:10.1016/j.atmosres.2008.09.015.

__ J. M. Straka, and E. N. Rasmussen, 2002: Direct surface thermodynamic observations within the rear-flank downdrafts of nontornadic and tornadic supercells. Mon. Wea. Rev., 130, 1692-1721, doi:10.1175/1520-0493(2002)130<1692: DSTOWT $>2.0 . \mathrm{CO} ; 2$.

- C. Hannon, J. Frame, E. Lancaster, A. Pietrycha, R. Edwards, and R. L. Thompson, 2003: Characteristics of vertical wind profiles near supercells obtained from the Rapid
Update Cycle. Wea. Forecasting, 18, 1262-1272, doi:10.1175/ 1520-0434(2003)018<1262:COVWPN $>2.0$. CO; 2 .

Marshall, T. P., D. Burgess, G. Garfield, R. Smith, D. Speheger, J. Snyder, and H. Bluestein, 2014: Ground-based damage survey and radar analysis of the El Reno, Oklahoma tornado. Proc. 27th Conf. on Severe Local Storms, Madison, WI, Amer. Meteor. Soc., 13.1. [Available online at https://ams.confex. com/ams/27SLS/webprogram/Paper254342.html.]

Moller, A. R., C. A. Doswell III, M. P. Foster, and G. R. Woodall, 1994: The operational recognition of supercell thunderstorm environments and storm structures. Wea. Forecasting, 9, 327-347, doi:10.1175/1520-0434(1994)009<0327:TOROST>2.0.CO;2.

Naylor, J., and M. S. Gilmore, 2014: Vorticity evolution leading to tornadogenesis and tornadogenesis failure in simulated supercells. J. Atmos. Sci., 71, 1201-1217, doi:10.1175/JAS-D-13-0219.1.

NCDC, 2013: Storm events database. Accessed 27 May 2015. [Available online at http://www.ncdc.noaa.gov/stormevents/ listevents.jsp? eventType $=\% 28 \mathrm{C} \% 29+$ Tornado\&beginDate $\mathrm{mm}=05 \&$ beginDate_dd $=31 \&$ beginDate_yyyy $=2013 \&$ endDate $\mathrm{mm}=06 \&$ endDate_dd $=01 \&$ endDate_yyyy $=2013 \&$ county $=$ ALL $\&$ hailfilter $=0.00 \&$ tornfilter $=0 \&$ windfilter $=000 \&$ sort $=$ DT $\&$ submitbutton $=$ Search\&statefips $=40 \% 2$ COKLAHOMA.]

Newman, J. F., and P. L. Heinselman, 2012: Evolution of a quasilinear convective system sampled by phased array radar. Mon. Wea. Rev., 140, 3467-3486, doi:10.1175/MWR-D-12-00003.1.

NOAA, 2012: WFO severe weather products specification. National Weather Service Instruction 10-511, 35 pp. [Available online at http://www.nws.noaa.gov/directives/sym/pd01005011curr.pdf.]

OFCM, 2010: National severe local storms operations plan. Office of the Federal Coordinator for Meteorology. Accessed 27 May 2015. [Available at http://www.ofcm.gov/slso/2010/slso2010. htm.]

2013: Doppler radar meteorological observations. Part A: System concepts, responsibilities, and procedures. FCMH11A-2013, Federal Meteorological Handbook No. 11, Office of the Federal Coordinator for Meteorology, $45 \mathrm{pp}$. [Available online at http://www.ofcm.gov/fmh11/fmh11parta/ pdf/FMH-\%2011\%20Pt\%20A\%20Feb\%202013\%20All.pdf].

Oye, R., C. Mueller, and S. Smith, 1995: Software for radar translation, visualization, editing, and interpolation. Preprints, 27th Conf. on Radar Meteorology, Vail, CO, Amer. Meteor. Soc., 359-361.

Rasmussen, E. N., 2003: Refined supercell and tornado forecast parameters. Wea. Forecasting, 18, 530-535, doi:10.1175/ 1520-0434(2003) $18<530$ :RSATFP $>2.0$.CO; 2 .

Scharfenberg, K. A., and Coauthors, 2005: The Joint Polarization Experiment: Polarimetric radar in forecasting and warning decision making. Wea. Forecasting, 20, 775-788, doi:10.1175/ WAF881.1.

Shabbott, C. J., and P. M. Markowski, 2006: Surface in situ observations within the outflow of forward-flank downdrafts of supercell thunderstorms. Mon. Wea. Rev., 134, 1422-1441, doi:10.1175/MWR3131.1.

Snyder, J. C., and H. B. Bluestein, 2014: Some considerations for the use of high-resolution mobile radar data in tornado intensity determination. Wea. Forecasting, 29, 799-827, doi:10.1175/ WAF-D-14-00026.1.

Tanamachi, R. L., P. L. Heinselman, and L. J. Wicker, 2015: Impacts of a storm merger on the 24 May 2011 El Reno, Oklahoma, tornadic supercell. Wea. Forecasting, 30, 501-524, doi:10.1175/WAF-D-14-00164.1.

Trapp, J. R., 2000: A clarification of vortex breakdown and tornadogenesis. Mon. Wea. Rev., 128, 888-895, doi:10.1175/ 1520-0493(2000)128<0888:ACOVBA > 2.0.CO;2. 
and B. F. Fiedler, 1995: Tornado-like vortexgenesis in a simplified numerical model. J. Atmos. Sci., 52, 3757-3778, doi:10.1175/1520-0469(1995)052<3757:TLVIAS >2.0.CO;2.

— , and R. Davies-Jones, 1997: Tornadogenesis with and without a dynamic pipe effect. J. Atmos. Sci., 54, 113-133, doi:10.1175/ 1520-0469(1997)054<0113:TWAWAD>2.0.CO;2.

Vasiloff, S. V., 2001: Improving tornado warnings with the Federal Aviation Administration's Terminal Doppler Weather Radar. Bull. Amer. Meteor. Soc., 82, 861-874, doi:10.1175/ 1520-0477(2001)082<0861:ITWWTF > 2.3.CO;2.

Whiton, R. C., P. L. Smith, S. G. Bigler, K. E. Wilk, and A. C. Harbuck, 1998: History of operational use of weather radar by U.S. weather services. Part II: Development of operational Doppler weather radars. Wea. Forecasting, 13, 244-252, doi:10.1175/1520-0434(1998)013<0244:HOOUOW>2.0.CO;2.

Wicker, L. J., and R. B. Wilhelmson, 1995: Simulation and analysis of tornado development and decay within a three-dimensional supercell thunderstorm. J. Atmos. Sci., 52, 2675-2703, doi:10.1175/ 1520-0469(1995)052<2675:SAAOTD $>2.0 . C O ; 2$.

Wilson, J., R. Carbone, H. Baynton, and R. Serafin, 1980: Operational application of meteorological Doppler radar. Bull. Amer. Meteor.
Soc., 61, 1154-1168, doi:10.1175/1520-0477(1980)061<1154: OAOMDR $>2.0 . \mathrm{CO} ; 2$.

Wood, V. T., R. A. Brown, and D. C. Dowell, 2009: Simulated WSR-88D velocity and reflectivity signatures of numerically modeled tornadoes. J. Atmos. Oceanic Technol., 26, 876-893, doi:10.1175/2008JTECHA1181.1.

Wurman, J., Y. Richardson, C. Alexander, S. Weygandt, and P. F. Zhang, 2007a: Dual-Doppler analysis of winds and vorticity budget terms near a tornado. Mon. Wea. Rev., 135, 2392-2405, doi:10.1175/MWR3404.1.

2007b: Dual- Doppler and singleDoppler analysis of a tornadic storm undergoing mergers and repeated tornadogenesis. Mon. Wea. Rev., 135, 736-758, doi:10.1175/MWR3276.1.

— K. Kosiba, P. Robinson, and T. Marshall, 2014: The role of multiple-vortex tornado structure in causing storm researcher fatalities. Bull. Amer. Meteor. Soc., 95, 31-45, doi:10.1175/ BAMS-D-13-00221.1.

Zrnić, D. S., and Coauthors, 2007: Agile-beam phased array radar for weather observations. Bull. Amer. Meteor. Soc., 88, 1753 1766, doi:10.1175/BAMS-88-11-1753. 